\title{
La metáfora como analizador social
}

\author{
EMMÁNUEL LIZCANO* \\ Dpro. Sociología I
}

UNED

\section{INTRODUCCIÓN ${ }^{1}$}

Todo discurso está poblado de metáforas, aunque la mayoría de ellas -y precisamente las más potentes- pasen desapercibidas tanto para quien las dice como para quien las oye. Es más, las metáforas no sólo pueblan los discursos sino que los organizan, estructurando su lógica interna a la par que sus contenidos. Lo relevante para el científico social está en que, a través del análisis de las metáforas, puede perforar los estratos más superficiales del discurso para acceder a lo no dicho en el mismo: sus pre-supuestos culturales o ideológicos, sus estrategias persuasivas, sus contradicciones o incoherencias, los intereses en juego, las solidaridades y los conflictos latentes... Es decir, el estudio sistemático de las metáforas puede emplearse como un potente analizador social.

Esbozaremos aquí las insuficiencias de los enfoques habituales sobre la metáfora para señalar cómo podrían reformularse con vistas a elaborar una técnica, una herramienta específica para el análisis social de textos y discursos. Podemos llamarle análisis socio-metafórico, aunque el método que se propone sea tan hermenéutico como analítico. Apuntaremos, en particular, cómo puede aplicarse a los textos y conceptos científicos, que son los que más resistencia ofrecen al análisis sociológico, si bien el alcance del método se extiende tanto a los conceptos de

* Emmánuel Lizcano es Licenciado en Matemáticas, Doctor en Filosoffa de la Ciencia y profesor de Sociología del Conocimiento en la Facultad de CC. Políticas y Sociología de la UNED.

${ }^{1}$ Este texto integra y amplía las exposiciones del autor en el VI Congreso Español de Sociología (La Coruña, septiembre'98), en la Facultad de Matemáticas de la Universidad de La Laguna y en la Escuela de Arquitectura de la Universidad de Las Palmas, éstas últimas dentro del ciclo sobre «Matemáticas y Cultura» organizado por el Seminario Orotava de Historia de la Ciencia (octubre'97). 
cualquier lenguaje técnico o especializado como a los conceptos que habitan en las lenguas vernáculas. Su originalidad estriba en que abre una perspectiva distinta de las habituales sobre la vida de los conceptos científicos: su génesis, su imposición o rechazo, su elaboración y articulación interna, su integración coherente en una teoría, sus transformaciones y circulaciones, su desaparición...

El interés sociológico de un análisis social de las metáforas está en que todos estos movimientos de los conceptos científicos se irán revelando, en el propio proceso del análisis, como movimientos sociales, al tiempo que los propios conceptos científicos -incluidos, por supuesto, los de las llamadas ciencias socialesvan apareciendo como entidades sociales. Es decir, no como entidades autónomas con un movimiento propio -el de la ilusoria lógica de la actividad teórica o del método científico-, no como entidades sobre las que lo social vendría después a ejercer desde fuera ciertas influencias o determinaciones, sino como entidades y movimientos metafóricos, $\mathrm{y}$, por tanto, -como veremos- constitutivamente sociales.

La génesis, formación y transformación de los conceptos científicos es descrita por la historia y prescrita por la filosofía (epistemología, metodología). Aquí trataremos de inscribirla. El análisis socio-metafórico no se desliza por la superficie de la ciencia ya escrita, haciendo de cada caso un mundo, ni impone a la ciencia por escribir sus prescripciones, haciendo de cada mundo un mero caso, sino que asiste -como una partera- al proceso de inscripción de la ciencia, a ése momento en que lo aún no dicho pugna por encontrar la palabra con que decirse; esa palabra poética que, con el tiempo, quedará inscrita en el concepto científico, en el cual deja su huella o marca, tras el cual se oculta al tiempo que lo tensa, prestándole su dinamismo.

\section{DOS HIPÓTESIS: EL CONCEPTO ES METÁFORA, LA METÁFORA ES SOCIAL}

Todos y cada uno de los conceptos científicos -y esta es la primera hipótesis fuerte del método- son conceptos metafóricos. $Y$ son metafóricos en varios sentidos: nacieron como metáforas, como tales metáforas son rebatidos y defendidos, como metáforas se reelaboran y refinan para resultar coherentes con el resto de metáforas latentes bajo los restantes conceptos del corpus teórico al que aspiran a incorporarse, como metáforas circulan de unas disciplinas a otras y como tales regresan a ese semillero de metáforas que es el lenguaje común del que emergieron, y como metáforas, en fin, sufren esa muerte que es el olvido, el olvido de su origen metafórico cuando su uso reiterado nos ha habituado a no ver en ellos sino conceptos puros, es decir, depurados de su ganga metafórica y social.

Metafórica y social. Pues, contra lo que presuponen las habituales teorizaciones sobre la metáfora, herederas en su mayoría de la conceptualización aristotélica, la lógica a que obedecen las metáforas $-y$, por tanto, la de los conceptos científicos que ellas animan- es una lógica social. Ésta es la segunda hipótesis fuerte del método: la actividad metafórica no es sólo una actividad linguiística (ya sea ornamental, como plantea la retórica clásica, ya estructural, como considera 
la llamada nueva retórica) sino también una actividad en la que se trasluce el contexto y la experiencia del sujeto de la enunciación; ahora bien, ese sujeto metaforizante no es tampoco un sujeto eterno y universal -trascendental, que diría Kant- a través del cual se manifiesta una lengua no menos eterna y universal, como parecen suponer Lakoff (1998), Johnson (1991) y Lakoff y Johnson $(1991)^{2}$ y sus hoy numerosos seguidores, sino un sujeto social, un sujeto concreto -histórica y socialmente situado- que se dirige a un oyente concreto en una situación concreta, un sujeto que, para construir sus conceptos y articular su discurso, selecciona unas metáforas y desecha otras en función de factores sociales (presupuestos culturales, intereses o aspiraciones de grupo o clase, alianzas o exclusiones, características de los destinatarios, prestigio social de los discursos que son fuente de los préstamos metafóricos, etc.).

La conjunción de ambas hipótesis da forma a la hipótesis central del análisis socio-metafórico: todo concepto es concepto metafórico y, por tanto, concepto social. En consecuencia, el análisis sistemático de los conceptos en tanto que metáforas es una vía privilegiada de acceso al sustrato social que constituye todo discurso y, en particular, permite traslucir la articulación social que vertebra ese discurso opaco por excelencia, ese discurso que hace del concepto 'claro y distinto' su seña de identidad: el discurso científico.

Que tal hipótesis es plausible, que es un proyecto viable el de intentar contrastar que bajo cada concepto científico late una metáfora, queda patente en trabajos como los emprendidos (tras las huellas de F. Nietzsche (1994) y M. Foucault $(1968,1978)$ ) por J. Derrida (1968a, 1968b) y G. Lakoff y M. Johnson (1991, 1998). El primero muestra el alcance -y los posibles límites logicos- de la hipótesis en el campo de los conceptos filosóficos, mientras que los segundos lo hacen con los conceptos habituales del lenguaje ordinario. El socio-análisis metafórico de los conceptos científicos permite una doble ampliación de estos enfoques. Por un lado, extender su alcance hasta los conceptos usados por las ciencias, por la matemática y por la lógica, tarea en parte ya emprendida por estudios aún dispersos y faltos de una metodología consistente y sistemática, como pueden ser los de A. Koyré (1955), E. Panofsky (1954), M. Black (1966), M. Hesse (1966), G. Holton (1978), Isabelle Stengers (1987), F. Hallyn (1987) o F. Vatin (1993). Por otro lado, enraizar el análisis metafórico en el sustrato social, político y cultural del que las metáforas emergen y en el que logran imponerse o resultan descartadas; esta segunda dimensión está más explorada en trabajos de tipo antropológico como los de D. Sperber (1978), los de D. Parkin (1982), los reunidos por J.W. Fernández (1991) o los que recopilan J.D. Sapir y J.C. Crocker (1977). La extensión del análisis metafórico en ambas dimensiones a la vez -hacia el sustrato social y hacia los conceptos científicos-

2 Estos autores conceden ciertamente a la metáfora una capacidad de modelar el conocimiento y la conducta en la que ya apunta cierta proyección social; no obstante, su naturalismo empirista funda toda actividad metafórica en una última instancia que sería la experiencia corporal, una experiencia que se supone genérica (el 'cuerpo humano') y, por tanto, a-histórica y a-social. No es difícil mostrar que tal experiencia del cuerpo está, a su vez, mediada socialmente y que, por tanto, 'el cuerpo' no es ninguna última instancia sino, también él, una construcción metafórica más. 
se ensaya sólo ocasionalmente en investigaciones como las de $\mathrm{K}$. Hayles (1984, 1993), D. Bloor (1998) o las mías propias (E. Lizcano, 1992, 1993, 1995, 1996).

\section{LA TRADICIÓN HEREDADA: EL LENGUAJE NATURAL(IZADO)}

La dificultad de un socio-análisis metafórico de los conceptos científicos no reside tanto en su objeto como en el peso de la tradición dominante en Occidente sobre estos asuntos, una tradición que -desde Aristóteles hasta la lingüística actual, pasando por toda la metafísica - ha consolidado como naturales y evidentes dicotomías del tipo logos/mithos, concepto/metáfora, razón/imaginación, lite$\mathrm{ral} /$ figurado, verdadero/falso, realidad/ficción, etc. ${ }^{3}$

Según Aristóteles (Poética, 21, 23-25; Retórica, 1410b y ss.), la metáfora se forma como fusión de una analogía. Dados dos campos semánticos, B y D, y establecida una semejanza entre ellos, $B \approx D$, se dice que $A / B=C / D$ es una analogía cuando $\mathrm{A}$ es una parte de $\mathrm{B}$ y $\mathrm{C}$ una parte de $\mathrm{D}$. Entonces pueden darse tres modos diferentes de metáforas (Figura 1): i) A de D, ii) C de B, iii) $A$ es $C$. (Evidentemente, para que estas metáforas tengan sentido es necesario que A y C estén elegidas adecuadamente). Veámoslo con un ejemplo del propio Aristóteles.

Si tomamos dos ámbitos diferentes, como el de la biología y el de la astronomía, y en su interior distinguimos dos campos, el de la vida individual (B) y del día solar (D), podemos establecer entre ellos una semejanza: «una vida es como un día» (o viceversa, pues la semejanza y la analogía, a diferencia de la metáfora, son reversibles). A partir de esta semejanza puede definirse la siguiente analogía 4: "vejez/vida = tarde / día», es decir, «la vejez es a la vida como la tarde es al día». De aquí se siguen metáforas de los tres tipos mencionados:

i) A de D: «la vejez del día» (de donde: «envejecía el día», etc.)

ii) C de B: «la tarde de la vida» (de donde: «en el ocaso de su vida», «aspecto crepuscular», etc.)

iii) A es D: «la vejez es un atardecer»

${ }^{3}$ Es de justicia resaltar que, justo en el momento en que esta tradición se reinstaura definitivamente en sus variantes racionalista y empirista, se abre una perspectiva alternativa que quedará sofocada por el ascenso de una burguesía que encuentra en el cogito cartesiano y en la razón ilustrada su expresión más cabal al tiempo que la forma de discurso más apropiada para su legitimación. Efectivamente, en el humanismo que se expresa en lengua castellana, y de modo muy singular en ese anti-Descartes que es Baltasar Gracián (véase Hidalgo-Serna, 1993), se perfila toda una teorización sobre la metáfora que incluye sus componentes cognitivo (es decir, como modo de conocimiento opuesto al que opera por conceptos abstractos) y social (es decir, como conocimiento enraizado socialmente a través de la situación concreta del discurso y del anclaje de éste en el habla popular). Serán la lectura de Gracián por Nietzsche, y las que después hagan de éste Foucault y Derrida, las que reactualicen hoy aquel enfoque frustrado en su mismo embrión.

${ }^{4}$ Por lo común, suele hablarse -y así lo haremos también nosotros- indistintamente de 'semejanza' y de 'analogía', sin reservar para ésta la estructura de proporcionalidad matemática que le asigna Aristóteles. 


\begin{tabular}{|c|c|c|c|}
\hline & Semejanza & Analogía & Metáfora (casos) \\
\hline Forma & $B \approx D$ & $\frac{A}{B}=\frac{C}{D}$ & $\begin{array}{l}\text { i) } \mathrm{A} \text { de } \mathrm{D} \\
\text { ii) C de B } \\
\text { iii) } \mathrm{A} \text { es C }\end{array}$ \\
\hline Ejemplo & vida $\approx$ día & $\frac{\text { vejez }}{\text { vida }}=\frac{\text { tarde }}{\text { día }}$ & $\begin{array}{l}\text { i) vejez del día } \\
\text { ii) tarde de la vida } \\
\text { iii) la vejez es la tarde }\end{array}$ \\
\hline
\end{tabular}

Figura 1

Así, para Aristóteles, «la metáfora consiste en trasladar a una cosa un nombre que designa otra, en una traslación de género a especie, o de especie a género, o de especie a especie, o según una analogía» (Poética, 1457 b 6-9). Este cosismo aristotélico, por emplear la expresión de Ortega, supone: a) un mundo constituido por cosas, estructuradas al margen del lenguaje que las nombra y las clasifica: la organización en géneros y especies está en la naturaleza de las cosas mismas, y b) que cada cosa es lo que es (principio de identidad) y no es otra (principio de no-contradicción). Sólo concibiendo cada cosa como "clara y distinta' -como hará después Descartes respecto a las ideas, llevando el acento de lo extramental a lo mental pero manteniendo idénticos presupuestos de claridad y distinción- podrá mantenerse la dicotomía ya habitual entre significado propio o literal y significado ajeno, impropio, ficticio, figurado o metafórico, según se atribuya a la cosa, respectivamente, un nombre que designa alguna propiedad específica suya (en cuyo caso podemos predicar tal nombre literalmente) o bien se le atribuya un nombre que lo es propiamente de otra cosa distinta.

Pero si se admite la posibilidad de que la cosa no sea fija y de-limitada, que no permanezca idéntica a sí misma, bien porque se altere (se haga literalmente otra, al modo heraclíteo), bien porque cabalgue entre dos géneros ${ }^{5}$, o bien porque en la constitución misma de la cosa intervengan modos de percepción y clasificación que varían según intereses, culturas o sensibilidades históricas, entonces las distinciones anteriores (sobre las que se basa toda la teorización heredada sobre la metáfora ${ }^{6}$ ) no se mantienen y se hace necesario reformular radicalmente

${ }^{5}$ La línea de demarcación entre significados propios e impropios, es decir, entre lo que puede predicarse con propiedad de algo y lo que no, se deduce de la pertenencia o no del tal algo a cierta especie o cierto género. Así, por ejemplo, para la tradición aristotélica, al constituir la aritmética y la geometría géneros diferentes ( $y$, por tanto, incomunicables entre sí), la traslación de conceptos o resultados de la una a la otra no puede ser sino una traslación impropia, es decir, metafórica. Pero será hablando impropiamente, es decir, metafóricamente, como Diofanto establecerá un puente entre ambos géneros sobre el que se construirá esa magnífica impropiedad que es el álgebra actual.

6 Baste recordar la definición habitual que formulara Dumarsais en su célebre Traité des tropes: «la metáfora es una figura por medio de la cual se transporta, por así decir, el significado propio de una palabra a otro significado que sólo le conviene en virtud de una comparación que reside en la mente». 
la cuestión, incorporando al corazón mismo del análisis aquellos factores sociales, culturales e históricos que sin cesar borran, alteran o difuminan los límites de las cosas ?.

Efectivamente, cuando la concepción tradicional de la metáfora se ve enfrentada a los cambios históricos y a la diversidad cultural, apenas se sostiene. De entrada, no todas la culturas estructuran el mundo en términos de géneros y especies; como contraejemplo, valgan las tradiciones del extremo oriente que, como la china, anteponen a ese modo de organización jerárquica de la realidad una clasificación in-mediatamente dual (yin/yang). De ahí que para la antigüedad china resulte natural o propio que el número se desdoble en positivo y negativo, mientras que en nuestra tradición los números naturales son sólo los positivos (el número es una especie del 'ser' y el ser es algo lleno, positivo) en tanto que los números negativos por fuerza han de ser impropios of ficticios (fictae llamaban a estas magnitudes los matemáticos renacentistas) ${ }^{8}$. Pero tampoco cuando distintas culturas estructuran la realidad según géneros y especies éstos coinciden en unos casos y otros (de modo que lo metafórico para una es literal para otra o viceversa) ni tienen por qué ser los géneros incomunicables entre sí (los 'leopardos cristianos' de los dorzé ¿son literales o metafóricos?). En general, lo que en cierta lengua $\multimap$ para cierto auditorio, o en cierto contexto- es un significado literal se convierte en otros en una expresión fuertemente metafórica (así, ese cero que en chino es, literalmente, una gota de rocio). No hay lenguaje natural, todo lenguaje es social.

A esta condición local de lo metafórico se añade una dimensión temporal o histórica, que hace que lo propio y lo impropio, lo literal y lo metafórico, se viertan continuamente lo uno en lo otro. Resulta así que ciertas metáforas devienen con el tiempo expresiones propias; por ejemplo, el concepto de 'trabajo' en mecánica (importado del lenguaje ordinario a través de la economía ${ }^{9}$ ), el de 'gas' (que empezó siendo 'caos' para van Helmont) en termodinámica, el de 'de-mostración' (ese 'mostrar' o 'poner ante la vista' propio de las construcciones geométricas) en lógica o el de 'raíz cuadrada' en matemáticas. Pero, también al contrario, ocurre que significados que eran bien propios para la ciencia establecida en un momento dado hoy nos ofrecen fuertes resonancias metafóricas, como los 'números sordos' medievales o el concepto de 'sal hermafrodita' de la química ilustrada, que llegará hasta hoy como 'sal neutra'. La propiedad o impropiedad de los significados lingüísticos depende del contexto -social, histórico e incluso

${ }^{7}$ Es de justicia señalar que el mismo Aristóteles (Poética, 1457b) también establece, junto a la división 'propio/impropio', la distinción 'corriente/insólito (o metafórico o decorativo o ficticio)'. Y aclara: «llamo 'corriente' al que [aquí] todos utilizan; 'insólito' al que utilizan los otros, de tal manera que el mismo nombre puede ser a la vez insólito y corriente, aunque no para los mismos [sujetos]: oíruvov, por ejemplo, es corriente para los chipriotas e insólito para nosotros». Frente al fijismo esencialista de la primera división, la definición de metáfora incorporaría ahora los usos y hábitos linguiísticos ('insólito' = lo que no suele decirse) y a los sujetos y contextos de enunciación (los chipriotas, todos [los de aquíi]). Consecuencia de ello sería una concepción relativista y social de la metáfora (lo que es corriente - propio- para los chipriotas es insólito $\multimap$ metafóricopara nosotros, o viceversa) muy próxima a la que aquí proponemos, aunque no sea la que desarrollará Aristóles ni la tradición occidental dominante.

8 Véase E. Lizcano (1983).

9 Véase F. Vatin (1993). 
circunstancial- en que esos significados se enuncian. Sólo desde una concepción esencialista de la realidad y del lenguaje, como algo que está ahí fuera, como algo dado de una vez por todas al margen de las representaciones sociales y los cambios culturales, como algo constituido por hechos y no por haceres, por significados y no por actividades significantes... puede sostenerse la concepción heredada sobre la metáfora.

\section{EL TRABAJO DE LA METÁFORA}

Sin abandonar por el momento esta concepción, es de interés para el análisis sociológico retener algunas de las aportaciones recientes de la lingüística cognitiva, para la cual la metáfora no es un mero recurso expresivo sino una forma de modelar la percepción y construir conocimiento. Destaquemos los siguientes puntos:

\subsection{Metáfora y cognición}

La semejanza y la analogía son operaciones simétricas: si ' $B$ es semejante -o análogo-a D' entonces ' $D$ es semejante -o análogo- a B', y viceversa. Sin embargo, la operación metafórica es asimétrica, atribuye sentido, está orientada: 'el atardecer de la vida' no es equivalente a 'la vejez del día'. En el primer caso concebimos la vida en términos astronómicos y aplicamos al ciclo vital la experiencia y el conocimiento que ya tenemos del ciclo solar, de modo que aunque nunca hayamos experimentado la vejez podemos hacernos una idea de ella a partir de la experiencia de los reiterados ocasos que sí hemos tenido ocasión de vivir y de los cuales, por tanto, tenemos cierto conocimiento adquirido. Un hecho biológico ("la vida') resulta, por así decirlo, astronomizado. En el segundo caso, por el contrario, percibimos el ciclo diurno como un ciclo vital, proyectamos sobre aquél nuestro conocimiento adquirido sobre éste, y es un fenómeno astronómico ('el día') el que resulta biologizado ('envejece'). Al polo de la analogía que se toma como punto de partida, y del que por tanto se extrae información, le llamaremos sujeto de la metáfora, siguiendo la terminología de Gracián, y a aquel otro polo sobre el que recae el desplazamiento metafórico le llamaremos término de la metáfora.

La metáfora funciona así como un mecanismo cognitivo que traslada al término el saber adquirido sobre el sujeto, prestando a aquél perfiles y contenidos que propiamente pertenecen a éste. Un ámbito que era desconocido o mal conocido puede así empezar a conocerse -a 'hacerse una idea'- mediante la luz que sobre él arrojan los conocimientos ya elaborados para otro ámbito diferente, sean estos conocimientos implícitos o explícitos. Esta última distinción viene a cuento de que la traslación metafórica no controla nunca todas las variables o aspectos que pone en juego; al hablar del 'envejecer del día' puede que el propósito explícito del hablante fuera sólo trasladar al día la idea de un final, de la inminencia de una muerte, pero no podrá evitar que todas las connotaciones y saberes implícitos que tanto él como sus lectores/oyentes tengan sobre la vejez resulten también pro- 
yectados inconscientemente sobre el ocaso: éste se percibirá como un momento de soledad y abandono si así es como habitualmente se percibe la vejez en su medio cultural, o se atribuirá al sol poniente esa imagen de plenitud y capacidad de discriminación (de los colores del paisaje, por ejemplo) que atribuyen a los ancianos otras sociedades.

El carácter orientado de la metáfora permite así distinguir el sujeto y el término, es decir, lo que, por una parte, una sociedad o grupo da por sabido (lo consabido) y por supuesto (sus pre-su-puestos) en un cierto ámbito, aquel saber que considera fundado y en el que se funda, y lo que, por otra parte, para esa sociedad o grupo es una incógnita, un punto ciego que pretende iluminar a la luz de lo que le es familiar y evidente. Pero el acceso que así se obtiene a los presupuestos, creencias y evidencias colectivas no se limita al ámbito estricto en el que opera la metáfora sino que se extiende a aquellos otros que se vinculan con él -a menudo inconscientemente- mediante la compleja red de connotaciones, supuestos implícitos, derivaciones necesarias, etc. que ese grupo ha tejido en torno al sujeto de la metáfora. Así, la multitud de conceptos metafóricos que pueblan la sociología funcionalista, al trasponer a la sociedad características de los organismos vivos, no sólo proporcionan un índicador de la operación ideológica subyacente (naturalizar lo social) sino que señalan también los rasgos concretos bajo los que esa operación se lleva a cabo: una determinada percepción de la salud de los organismos (lo que se tiene por normal y por patológico), la concepción del cuerpo dominante en medicina y biología (la 'estructura' como 'morfología', la 'función' como 'fisiología'), la valoración de rasgos como la 'estabilidad' o las 'necesidades', etc. En contraste, el funcionalismo platónico, al metaforizar la jerarquía de las clases sociales (sabios, militares y productores/comerciantes) en términos orgánicos (cabeza, corazón y vientre), nos permite acceder a un saber sobre el cuerpo bien diferente. (E1 lector puede intentar reconstruir los conceptos fundamentales de una supuesta sociología funcionalista china en función de los conocimientos que tenga sobre acupuntura y otras técnicas corporales afines).

\subsection{De la metáfora al símbolo}

La antropología simbólica de D. Sperber (1978) recoge el dinamismo social que hemos observado en la actividad metafórica subrayando el papel de símbolo que, en ciertas circunstancias, llega a adquirir el sujeto de la metáfora. Para Sperber, lo simbólico no es tanto un repertorio de objetos singulares, que serían los símbolos, como un dispositivo de conocimiento que actúa cuando el dispositivo conceptualizador fracasa o resulta insatisfactorio. El dispositivo simbólico no actúa así sobre unos símbolos predefinidos, a los que interpretaría según la ocasión, sino sobre problemas o situaciones - del género que sean-para los que no hay conceptos elaborados, para los que el repertorio semántico de una lengua no dispone de términos. Se trata, por tanto, de un dispositivo para la construcción de nuevos significados.

Así, por ejemplo, ante el intento de pensar conceptualmente un olor (que sería lo que hemos llamado término de una metáfora aún por establecer), nuestra cultura 
carece de expresiones adecuadas. Al tratarse de una cultura fundamentalmente óptica, todo la riqueza conceptual desarrollada para los colores y las formas no admite parangón con la escasa enciclopedia semántica elaborada, por ejemplo, para las sensaciones táctiles y no posee ni un sólo término específico para el campo de los olores. $\mathrm{Si}$, pese a ello, insistimos en pensar ese olor y conceptualizarlo, se produce en nuestra mente un doble movimiento, a la vez afectivo, social e intelectual. Primero, un movimiento de focalización en una imagen, sensación o concepto próximo (el sujeto de la metáfora que ya estamos estableciendo) que funciona como correlato analógico del olor (término) que se quiere pensar. Segundo, una cascada de evocaciones y connotaciones convocadas por el poder atractor de aquel foco (o sujeto), sobre el cual vienen a precipitar o condensarse, contribuyendo a darle forma y definición. Así, un cierto olor a incienso acaso nos traiga la imagen de una iglesia, sobre la cual precipitarán toda una serie de recuerdos y asociaciones, de modo que esa iglesia funcionará como símbolo de aquel olor; y si intentamos entonces definir éste en términos conceptuales, las expresiones que utilizaremos para ello provendrán de los campos activados por tales evocaciones, quizá expresiones que se refieran a embriaguez, silencio, penetración o acritud, sacralidad... El término de la metáfora (la conceptualización del olor) quedará así definido en términos del sujeto que así ha llegado a adquirir categoría de símbolo.

La actividad metafórica y simbolizante es, por tanto, un mecanismo de resolución de problemas. En cuanto mecanismo es universal, y se activa por igual en el hombre de la calle ante el problema de conceptualizar un olor que en el físico teórico que se enfrenta a la 'materia oscura'. Pero la particular solución que cada individuo o grupo arbitre para el problema inicial resulta socialmente cargada con esa tupida red de adherencias evocativas y connotativas que se han condensado en el símbolo y que provienen tanto de la experiencia, creencias y expectativas personales del sujeto de la interrogación como de la experiencia, creencias y expectativas colectivas de la cultura o grupo a los que pertenece ${ }^{10}$. Veamos cómo afecta esa carga social a la resolución -que se revelará metafórica- de un problema matemático tan elemental que nos es tan natural como la misma salida del sol por las mañanas: el problema de sustraer o restar dos números entre sí.

\subsection{La metáfora de la resta: ¿sustraer u oponer?}

Para quienes hemos sido socializados en ciertas habilidades técnicas (gratuitas y obligatorias), 'sustraer el número A del número B' es una expresión bien literal,

10 De la generalidad de este dispositivo doble de focalización/evocación da una idea el que se corresponda bastante aproximadamente con el doble movimiento de desplazamiento/condensación que - para Freud-permite interpretar el simbolismo onírico, así como también con la articulación metáfora/metonimia que -para Jakobson- estructura cualquier forma de lenguaje. La ventaja que, para nuestro propósito, tiene el modelo sperberiano sobre los otros dos es doble, pues -por un ladopermite incorporar factores tanto individuales como colectivos, tanto intelectuales como emocionales, y -por otro lado- se trata de un modelo que pone el énfasis en lo cognitivo, en lo que dicho dispositivo tiene de específico para construir conceptos y conocimientos nuevos. 
una expresión que incluso podría ponerse como ejemplo de lo que no es una expresión metafórica o poética. Sin embargo, tuvieron que existir ciertos antepasados nuestros para los que una expresión así aún no tenía sentido. Situémonos en el momento en que el 'genio griego' aún no ha incorporado a su enciclopedia matemática el concepto que hoy nombramos como 'resta' o 'sustracción', y se encuentra en la situación de encontrar un nombre para esa operación. El matemático griego se ve obligado a seleccionar un término del lenguaje común u ordinario, pues el vocabulario técnico aún no dispone para ello de un término específico. El hecho de que, de entre todos los términos posibles de la enciclopedia semántica ordinaria a su disposición, seleccione precisamente uno y no cualquier otro nos indica el sujeto preciso sobre la que el modo de pensar griego focaliza el modo en que se enfrenta al problema de 'restar'. Pues bien, la expresión que selecciona el matemático griego es el verbo aphairéo ( $\alpha \phi \alpha \imath \rho \varepsilon ́ \omega)$, cuyo modo de operar se nombra como aphaíresis. En griego común este tipo de expresiones se utilizaban para actividades como 'extraer', 'sacar', 'arrancar', 'privar', etc. Implican, pues, la existencia de cierta sustancia o sustrato del cual se sustrae una parte. Así, cuando Euclides habla de 'sustraer un número de otro' es como si extrajera o arrancara de la sustancia en que consiste el primero esa parte que cuantifica el segundo, de manera que -tras la operación de sustracción/extracción- queda un resto o residuo. Aquí tenemos la operación metafórica fundamental que determinará todas las posibilidades -pero también las imposibilidades- que la operación de restar abre -pero también cierra- en la matemática griega clásica ${ }^{11}$.

Una vez focalizada la resta en la imagen de la extracción, sólo un detenido repaso por la cultura griega de la época puede decirnos qué evoca en la mente del ciudadano común la presencia de esa imagen. El estudio de los diferentes contextos de uso del término seleccionado como foco puede ser un buen camino para ello. Y no deja entonces de resultar chocante -pero harto significativo- que sea ése mismo término, el de aphaíresis, el utilizado por Aristóteles para referirse a lo que solemos traducir como abstracción. Así pues, el matemático griego sustrae números como el escultor extrae fragmentos de un bloque de piedra, como el filósofo abstrae un concepto de otro. Cuando el concepto aphairesis, que ha focalizado el problema -aún sin nombre- de restar números, actúe como sujeto de la metáfora 'sustraer números' o 'sustracción de números', proyectará sobre la solución del problema (la 'resta') ${ }^{12}$ todo ese aglomerado de evocaciones y connotaciones que

"Los límites que la selección de ese sujeto metafórico impone a la operación matemática de 'la resta', aún siendo culturales, son tan intrínsecos a la actividad matemática misma que todavía veintitantos siglos más tarde Kant discute, en su Ensayo para introducir en la filosofía el concepto de magnitud negativa, la legimidad de restar entre sí ciertos números. La asunción de esa metafóra como evidencia literal en nuestra tradición cultural determina numerosas dificultades matemáticas, especialmente en la resolución de ecuaciones, como puede comprobarse en los artículos Équation y Négatif de aquella Enciclopedia que fue emblema de la llustración (para más detalles, E. Lizcano, 1983). Ya entrado el s. XIX, Lazare Carnot aún demostrará (!) que "para obtener realmente una cantidad negativa aislada, habría que quitar (retrancher) de cero una cantidad efectiva, sacar (ôter) algo de nada: operación imposible». La inercia de algunas metáforas científicas es una inercia casi geológica.

12 La terminología gracianiana resulta singularmente adecuada para un enfoque socio-cognitivo. El 'término' que dará nombre al nuevo concepto que se trataba de acuñar es precisamente el 
se han condensado sobre el foco 'extracción'. Y como quiera que tales adherencias son a su vez condensaciones metafóricas, se pone así en circulación toda una red de metáforas concomitantes que van trasvasando al campo matemático sentidos procedentes de campos diferentes: sentidos estéticos, filosóficos, de la vida cotidiana...

Ahora bien, si el matemático sustrae números para llegar a obtener un resto como, por ejemplo, el escultor extrae material de un bloque de piedra para conseguir ese resto que es la estatua, la actividad del primero queda iluminada, pero también ensombrecida, por las características propias de la práctica del segundo. La lógica propia del esculpir pasa a gobernar, en este punto, la lógica interna de la actividad matemática. Así, por ejemplo, es evidente que el escultor nunca podrá extraer tanta sustancia como la que contiene el bloque, pues en tal caso se quedaría sin sustrato para su estatua, por lo tanto (y este 'por lo tanto' hace referencia a una causalidad metafórica) tampoco podrá sustraerse de una magnitud ${ }^{13}$ otra tan grande como ella. Tan carente de sentido sería la actividad del escultor que pulveriza por entero su bloque de piedra hasta quedarse sin estatua como la del matemático que, tras efectuar las sustracciones ' $4-1=3$ ', ' $4-2=2$ ' y ' $4-3=1$ ', intentara proseguir hasta ' $4-4$ ', momento en el que se quedaría sin resto ${ }^{14}$. El 'genio griego' no puede concebir nada parecido a lo que hoy nosotros llamaríamos 'cero'. Y es el análisis metafórico de uno de sus conceptos matemáticos el que nos lo revela y nos sugiere las razones sociales y culturales de esa incapacidad.

Pero, ¿qué ocurriría si nuestro escultor tallara su estatua para un público que en la desaparición de la materialidad de la obra experimentara, no la angustia del griego ante la irrupción del vacío, sino un especial goce estético? ${ }^{15}$. Ocurriría sencillamente que nos habríamos trasladado, por ejemplo, a la China antigua, y que esta traslación local y social habrá implicado un cambio radical en la traslación metafórica con que ahora se intente pensar el mismo problema: el problema de restar entre sí dos números.

término de la metáfora (en este caso, el término recibe el nombre del sujeto: 'sustracción', si bien en aquél lo que se sustraen son números en vez de sustancia).

13 Ya se entienda tal magnitud como segmento (al modo aristotélico-euclideo), ya como multitud de unidades, cuentas o psofoi (al modo pitagórico). En cualquier caso, el número griego es un número sustancial, lleno de sustancia, un número pletórico (el mismo término $\pi \lambda \hat{n} \theta 0 \varsigma$ que significa 'masa', 'multitud' o 'abundancia', se usa también para 'cantidad' y 'número').

14 Esta evidencia matemática es de tal rotundidad para el espíritu griego que en ella fundamentará Aristóteles uno de sus argumentos contra la existencia del vacío (Physica, IV). Obsérvese cómo el cierre del círculo metafórico se convierte en círculo vicioso: la traslación metafórica de la extracción (física) a la sustracción (matemática) determina la imposibilidad de lo que hoy llamaríamos 'cero', y la traslación metafórica de este 'hecho' (matemático) otra vez al campo físico permite concluir la imposibilidad del vacío. Al cabo de este periplo, el argumento aristotélico se resumiría en: el vacío no existe porque ningún escultor sería tan torpe o tan insensato como para destruir por completo el bloque de piedra del que estaba extrayendo una bella estatua.

15 Esta conjetura no es ninguna extravagancia impropia, más o menos justificable por su presunta virtud heurística, sino un hecho bien literal: «Con un modesto pincel, recrear el cuerpo inmenso del vacío». Así es como expresa el pintor Wang Wei el objetivo de un arte con fuerte arraigo popular en la tradición china. (Véase, F. Cheng, 1994). 
En la China de los primeros Han podemos observar que el problema de 'restar' una cantidad de otra se plantea de manera bien distinta: el foco que ahora actúa como sujeto de la traslación metafórica no es el de la 'sustracción' sino el de la 'destrucción mutua' (xiang xiao) entre dos entidades que se oponen entre sí. En China dos números no se restan como si la sustancia del uno se extrajera de la del otro sino como si esos dos números fueran dos contrarios que se oponen o enfrentan el uno al otro. Por lo tanto (y este 'por lo tanto' vuelve denotar una causalidad metafórica), ahora sí es posible que dos fuerzas enfrentadas, como pueden ser las de dos ejércitos enemigos, se 'hagan desaparecer' o 'se aniquilen' (jin) la una a la otra si las fuerzas están 'equilibradas' ( $q$ i tong). Todos estos términos en cursiva, propios del campo bélico, son los que aparecen en los textos matemáticos clásicos para nombrar esa operación que nosotros, bajo evidentes reminiscencias griegas, llamamos 'resta'. Y por eso en estos textos sí podemos encontrar abundancia de ejemplos en los que la operación '4-4' tiene pleno sentido. Como también lo tiene la operación ' $4-5$ ' si ese signo 'menos' es el término de una metáfora que tiene como sujeto la 'oposición de contrarios': tan plausible es que si 4 palillos rojos se enfrentan dos a dos - 'aniquilándose mutuamente'- con 5 palillos negros acabe sobreviviendo 1 palillo negro, como que si son 5 los rojos y 4 los negros sea 1 rojo el superviviente. En cambio, ¿qué haría nuestro escultor griego si, una vez aniquilado todo el bloque de piedra, se le pidiera que siguiera extrayendo material? Diría que es absurdo, como seguirá diciéndolo de los números negativos D'Alembert en los artículos mencionados de la Enciclopedia.

La diferente construcción metafórica, en uno y otro caso, del concepto 'resta' (cuyas raíces socio-culturales exploramos en E. Lizcano, 1993) condicionará el desarrollo de las matemáticas durante más de veinte siglos, aunque las habituales historias de esta disciplina ignoran por completo esas condiciones sociales determinantes para ofrecer a cambio las habituales reconstrucciones ad hoc, en las que los problemas y sus conceptualizaciones se presentan como impulsados por una racionalidad interna que les fuera propia cuando esa racionalidad es impropia, metafórica.

\section{EL SABER COMO IGNORANCIA}

Hasta aquí hemos atendido a la dimensión poética de los conceptos científicos, al proceso de su hacerse ( $\pi \circ \imath \varepsilon \dot{\varepsilon} \omega=$ 'hacer', 'construir'). El socio-análisis metafórico asiste entonces al momento en que los conceptos aún se están acuñando, sea en la mente de un pensador individual, sea en las réplicas y contrarréplicas que se cruzan en un debate científico en el que aún no se manejan conceptos asumidos por la comunidad científica implicada. Sin embargo, la mayoría de los conceptos científicos se nos presentan no en su hacerse sino como 'hechos', como términos propios y no como términos de una metáfora original constitutiva, como lo que se han llamado 'cajas negras' en cuyo contenido no puede estar indagando el investigador que los emplea sin verse permanentemente obstaculizado, cuando no paralizado. El concepto es útil en la práctica científica ordinaria 
precisamente cuando se olvida su carácter de concepto, es decir, cuando se olvida que ha sido previamente concebido, y concebido metafóricamente. Por eso dice Nietzsche $(1990,25)$ que es «en virtud de esa inconsciencia, de ese olvido [como] se adquiere el sentimiento de verdad». Los conceptos científicos, para que funcionen sin problemas dentro de cierto paradigma, exigen ser tratados como cajas negras cuya constitución interna debe ignorar el científico si no quiere empantanarse permanentemente ${ }^{16}$.

\subsection{El concepto como síntoma}

Dos son los niveles de depuración y olvido que hacen posible el uso y circulación de los conceptos. El primero es intrínseco a la actividad misma de la metáfora. El término de ésta recibe propiedades del sujeto que no son apropiadas para el objetivo que se persigue al metaforizar, propiedades que deben depurarse, dejarse de lado y olvidarse. La vejez es un atardecer... pero no es un atardecer; para que la metáfora funcione debemos abstraer o sustraer de la imagen de un atardecer propiedades no pernitentes para el efecto metafórico (como el que cierre un ciclo de 24 horas). La 'mecánica celeste' newtoniana traslada a los cielos o al cosmos toda una serie de características y problemas propios de las máquinas que en su sociedad empiezan a adquirir un papel relevante: la necesidad de un constructor, la regularidad de su funcionamiento, el consumo de energía, la reversibilidad del tiempo, o la optimización de su rendimiento y su capacidad de producir trabajo (lo que trasladará al cosmos conceptos tan puritanos como el de 'esfuerzo' $(\mathrm{F}=\mathrm{m} \cdot \mathrm{a}) \mathrm{o}$ como el de 'trabajo' $(\mathrm{T}=\mathrm{F} \cdot \mathrm{s})$ ). Pero no siempre se considerarán atribuibles al cosmos todos esos rasgos de las máquinas, unas veces se ignorarán unos y otras otros. Este primer nivel de olvido (de los aspectos no pertinentes de la analogía subyacente) es condición necesaria para que funcione la metáfora.

Pero hay un segundo nivel de olvido más decisivo todavía, pues relega lo olvidado a un nivel inconsciente -como ya apuntara Nietzsche anticipando a Freud- desde el cual actuará con mayor eficacia. Se trata ahora de olvidar, no sólo los rasgos no pertinentes de la analogía latente, sino de olvidar también la existencia misma de tal analogía. Comoquiera que era esa analogía la que daba sentido -al dar orientación- a la metáfora, ésta queda ahora literalmente sin sentido, reducida a un puro significado, un mero concepto opaco que no deja traslucir el desplazamiento metafórico que, sin embargo, le presta su vitalidad. Los conceptos son así metáforas que hemos olvidado que lo son. Veamos un ejemplo.

En la metáfora 'mecánica celeste' subyace la interacción entre dos campos, el de la máquina y el del cosmos. Cada uno de ellos por separado, antes de venir a mezclarse/distinguirse mediante el establecimiento de la metáfora mencionada, parecen constituir campos autónomos, donde los conceptos propios de cada campo se nos presentan como conceptos puros, no metafóricos. Sin embargo, ya

16 Cuando el científico reflexiona sobre sus conceptos, en lugar de limitarse a usarlos tal y como le han llegado, ya institucionalizados, se arriesga a dejar esa ignorancia al descubierto (véase el Corolario sobre Sokal al final del artículo). 
el concepto 'cosmos' es un concepto metafórico: $\kappa o \sigma \mu \varepsilon ́ \omega$ era el verbo empleado en la antigua Grecia para designar, entre otras cosas, la actividad del jefe militar al disponer sus tropas para la batalla. La relación que establece el griego con una naturaleza entendida como 'cosmos' se manifiesta así como una relación bélica: un lugar a ordenar y conquistar. Con el paso de los siglos, esa analogía subyacente se ha olvidado y hemos llegado a tener al concepto 'cosmos' como un concepto neutro, no valorativo; sin embargo, aquel sentido original sí ha permanecido adherido al concepto, pero a nivel inconsciente, y seguramente no es ajeno a él el modo en que nuestra civilización ha orientado su actitud hacia la naturaleza desde entonces hasta nuestros días. La identificación de la metáfora que alimenta un concepto cuya condición metafórica nos había pasado desapercibida permite así considerar tal concepto como un síntoma a través del cual se manifiestan las fuerzas latentes que lo animan.

\subsection{Metáforas zombies}

Cabe así hablar de metáforas vivas y metáforas muertas. Las primeras se caracterizan por mantener viva la ficción, la conciencia del 'como si', al no ocultar la analogía que las hace posibles. Son las metáforas que se presentan como 'hallazgo poético', pero también las que impulsan el momento poético, intuitivo o creativo de las ciencias: la formulación de hipótesis o conjeturas, el tratamiento de un problema geométrico como si fuera algebraico, etc. Ante una metáfora viva el lector/oyente es consciente de que está, efectivamente, ante una metáfora. Metáforas muertas son, por el contrario, las que no se perciben ya como tales metáforas, sino como conceptos bien definidos, cuando no ocurre que pasan por ser la realidad misma (como ocurría con el 'cosmos', antes de ponerlo entre comillas). Ahora bien, este olvido de la ficción original, lejos de desactivar la potencia metafórica, la refuerza, pues al mantenerla inconsciente impide la percepción de la tensión que bulle bajo la metáfora y, en consecuencia, hace imposible el control sobre la ficción que la instituye. Cuando usamos este tipo de conceptos, más bien son ellos los que nos usan, imponiendo a nuestro discurso una lógica que nos es ajena y escapa a nuestro control. Propiamente, no se trata tanto de metáforas muertas cuanto de metáforas zombies.

Ciertamente, estas metáforas muertas -0 , al menos, muchas de ellas- fueron en un momento metáforas vivas, siendo -tanto sus autores como los oyentesconscientes de su carácter ficticio, pero el tiempo y el uso las fueron desgastando, pasando a formar parte del acervo léxico de la lengua común y de los conceptos y operaciones formales y habituales de las ciencias. De ahí que su identificación como tales metáforas, su puesta entre comillas, sea el primer paso para poder recorrer en sentido inverso su historia y descubrir en ella la acumulación de adherencias culturales que aún hoy le prestan secretamente un sentido que escapa a la conciencia ${ }^{17}$.

17 Esa de-construcción de los conceptos para excavar las metáforas raíces constituye el proyecto nietzscheano de una arqueología o una genealogía, que Foucault (1978) y Derrida (1989ª 
$\mathrm{Si}$, en consonancia con este enfoque, pensamos las metáforas como instituciones sociales, la metáforas vivas pondrían de manifiesto la actividad social instituyente mientras que las metáforas muertas reflejarían lo instituido de todo proceso de institución. En las primeras, la puesta en conexión analógica de dos campos semánticos concretos no es arbitraria, no se debe -0 , al menos, no se debe sólo- al 'genio individual' o a la 'feliz ocurrencia' del poeta o el investigador. Son cada sensibilidad cultural y cada contexto concreto (por ejemplo la meta que persigue cierta línea de investigación y las hipótesis que asume) los que hacen posible que, al instituirse una metáfora, ciertos campos puedan sentirse como próximos -y, por tanto, susceptibles de analogía-o, por el contrario, imposibles de conectar (no es otra, por ejemplo, la función que tienen los tabúes sobre los que se instituye cada sociedad). Aunque la primera formulación de cierta metáfora sea una ocurrencia individual, no por ello la operación metafórica deja de ser una operación social. Primero, porque sólo determinadas configuraciones y sensibilidades sociales hacen posibles - o, por el contrario, impensables- determinadas ocurrencias. Segundo, porque esa metáfora supera el carácter efímero de la mera ocurrencia y pasa a ser moneda corriente sólo cuando su uso se generaliza, es decir: 1) cuando tiene sentido para -y permite decir algo nuevo a- una comunidad concreta, ya se trate de una comunidad lingüística amplia en un cierto estado de evolución de la lengua, ya sea una comunidad lingüística restringida, como lo son las comunidades profesionales o científicas; y 2) cuando consigue imponerse a otras posibles metáforas en pugna, imposición que -por su propia condición- es en buena medida retórica, es decir, causada por la mayor capacidad persuasiva que para cierta comunidad de hablantes tiene esa metáfora sobre las metáforas eventualmente concurrentes.

La principal dificultad que tuvieron que vencer los conceptos del electromagnetismo en el momento de instituirse fue el rechazo social, compartido por la comunidad científica, a cuanto evocara 'acción a distancia' o tuviera cualquier otra connotación mágica o animista, creencias de una época que ciertos grupos querían superar. En la Grecia clásica, era tabú correlacionar analógicamente el campo del número y el de las formas geométricas, que se percibían como fuertemente heterogéneos, pero la quiebra del mundo clásico y la emergencia de otras sensibilidades culturales reprimidas por aquél, sí permitirá ya a Diofanto establecer esa analogía y poner los fundamentos del álgebra. En cambio, los campos de la geometría y de la biología sí se percibían como campos asemejables, susceptibles en consecuencia de alumbrar metáforas verosímiles, por lo que pudieron instituirse, allí y entonces, conceptos metafóricos tan fuertes como los de 'raiz de un cuadrado' o 'vigor ( $\delta v$ vo $\mu l \varsigma$ = 'potencia') de un segmento'. Son factores sociales y culturales los que restringen así el abanico de todas las analogías y metáforas posibles, presentando a la intuición de la actividad instituyente tan sólo un número limitado de posibilidades abiertas. El momento instituyente o vivo de la actividad metafórica mantiene una cierta conciencia del 'como si',

1989b) pondrán posteriormente en marcha. Véase, para una arqueología de los conceptos matemáticos, E. Lizcano (1992). 
aspira a establecer una solución verosímil, en el interior del marco de creencias, intereses y expectativas de un cierto grupo o cultura.

La imposición de cierta metáfora viva sobre eventuales metáforas alternativas, o sobre otras metáforas muertas a las que consigue sustituir, generalizará y reiterará su uso hasta que, con el paso del tiempo, se convierta en una expresión habitual -para cierta comunidad lingüística- y llegue a tenerse como expresión propia, no metafórica. En este punto la fluidez del trasvase de significados se solidifica -mejor diríamos: se con-solida- y la conciencia del 'como si' queda relegada al inconsciente del grupo social, proceso en el cual lo verosímil pierde lo que tenía de 'símil' para quedar instituido como mero 'vero': la nueva forma de lo verdadero. El concepto así consolidado, ahora metáfora zombie, actuará ya como cualquier otra institución social para quienes, no habiendo asistido al proceso de su hacerse, lo asuman como un hecho: la regularidad y reiteración de su uso reforzará el consenso en torno a su veracidad e incluso su naturalidad, su internalización por los individuos fijará ciertas creencias y modos de conducta, su carácter coercitivo reprimirá cualquier intento de cuestionamiento, relativización o perspectiva alternativa, su condición de evidencia compartida normalizará los discursos y las conductas, su sustrato (metafórico) inconsciente será fuente de consecuencias no previstas y no buscadas, etc.

En este proceso de fosilización progresiva de las metáforas para devenir conceptos técnicos o términos del lenguaje ordinario, la carga simbólica del sujeto de la metáfora que actuó originariamente como foco resulta desecada en la categoría del mero signo lingüístico, la tensión de la ficción que aún latía en la metáfora se distiende en la -aparente- estanqueidad del concepto, la polaridad de la analogía subyacente se disuelve en pura igualdad o identidad. McCloskey (1990, $111 \mathrm{ss}$ ) ha puesto de manifiesto cómo el signo matemático de 'igualdad' que aparece en las 'funciones de producción' oculta la analogía implícita que permite asociar los contenidos de cada uno de ambos miembros de la ecuación.

Efectivamente, la forma actual de expresar las ecuaciones matemáticas presenta un buen ejemplo de este proceso de paso del símbolo al signo, de la analogía significativa (' $\approx$ ) a la igualdad ('=') in-significante. Pues, ¿qué es el signo '=' que une/separa los términos de una ecuación sino el vestigio de aquel 'como si' que enlazaba los campos que venía a asemejar la analogía? Buena prueba de ello es que en toda la matemática de estirpe griega, incluida la proverbial capacidad del álgebra simbólica (!) árabe para la abstracción, la discusión de la ecuación de segundo grado $\mathrm{ax}^{2}+\mathrm{bx}+\mathrm{c}=0$ no se hará a partir de esta sencilla expresión (como se hace hoy incluso en la escuela elemental) sino a partir de una engorrosa distinción entre tres casos posibles, cada uno de los cuales se discutía por separado: i) $a x^{2}+b x=c$, ii) $a x^{2}=b x+c$, iii) $a x^{2}+c=b x$. La razón es clara, y -una vez más- metafórica: a ambos lados de la ecuación es necesario que haya 'algo' pues para poder establecerse una analogía es preciso que haya dos campos que se pongan en relación; entre un campo (' $a x^{2}+b x+c$ ') y una ausencia de campo (' 0 ') no hay relación ('ecuación') posible. Sólo cuando esa ausencia sea pensable como un campo semántico en sí mismo (lo que no ocurrirá hasta que haya un cambio cultural radical o que nos traslademos varios siglos atrás a una cultura radicalmente diferente como la china) podrá pensarse y escribirse algo 
tan sinsentido - para una mentalidad como la griega- como equiparar 'algo' y 'nada', es decir, escribir ' $a x^{2}+b x+c=0$ '. En general, podríamos decir que bajo toda ecuación late una analogía que soporta una metáfora. Ignorarlo es lo que permite trabajar con la ecuación como si fuera un mero instrumento, neutro y no valorativo, pero es lo que permite también que los intereses, los valores y los pre-juicios cristalizados en el signo ' $=$ ' no dejen de actuar aunque nos pasen desapercibidos.

\subsection{Socio-análisis metafórico del lenguaje ordinario}

Aunque este tipo de análisis se muestra especialmente apropiado ante los conceptos técnicos y científicos, para los que el mecanismo de depuración y olvido es sistemático y corporativo, no deja de mostrar su virtualidad ante los términos y expresiones del lenguaje corriente y moliente, donde tal mecanismo actúa de modo espontáneo en el molerse y depurarse de las palabras al correr de boca en boca. Con ocasión de cierta exposición oral de estas cuestiones ante un público de físicos, matemáticos e ingenieros, un oyente me lanzó a bocajarro: «De verdad, ¿tú crees que vale la pena el tiempo que has invertido en esto?». Tras el inicial sobresalto, con su benévola colaboración y la ayuda del resto improvisamos un análisis metafórico de su propia expresión, cuyo resultado podría transcribirse como sigue.

Una expresión habitual como «Vale la pena el tiempo que has invertido en esto» sólo revela todo su sentido al desenterrar en ella dos metáforas latentes: $m_{1}$ ) 'Invertir tiempo', $\mathrm{m}_{2}$ ) 'Valer la pena'. Estas metáforas, a su vez, se construyen desde las analogías respectivas entre los campos (ver Figura 2): $a_{1}$ ) Tiempo y Dinero $\left.(T \approx D), a_{2}\right)$ Pena y Bienes $(P \approx B)$, entendiendo por 'bienes' el «conjunto de pertenencias que poseen algún valor».

La correlación entre tiempo y dinero aporta a cada uno de ambos polos características que, propiamente, pertenecen al otro; así, expresiones como 'ahorrar tiempo', 'perder el tiempo' o 'tiempo invertido', hablan del tiempo como dinero ( $T$ como D), es decir, toman al dinero como sujeto proyectando sobre el tiempo (ahora término) la experiencia que tenemos de aquél: el tiempo es algo que se ahorra, se pierde o se invierte. Inversamente, la percepción del dinero como algo que fluye ('flujo de capitales', 'liquidez monetaria') y se va de entre las manos proyecta sobre el dinero una determinada experiencia del tiempo (D como $\mathrm{T}$ ). La institucionalización de ambos grupos de metáforas en nuestra cultura contamina a cada uno de los campos ( $T$ y $D$ ) de la manera en que se experimenta el otro, hasta el punto de que llegan a percibirse como sinónimos $(\mathrm{T}=\mathrm{D})$ : hablamos de 'asegurar la vejez' en lugar de 'asegurar el dinero para la vejez' porque esta segunda expresión ha llegado a ser un pleonasmo: para aquellos grupos sociales en los que los seguros y la búsqueda de lucro se dan por supuesto, acumular años es acumular dinero.

Sin embargo, la posibilidad de que esta analogía resulte tan fluida arraiga en la convergencia de una serie de sustratos socio-culturales que han permitido unas muy singulares concepciones del tiempo y del dinero. Sólo desde una cultura que, 


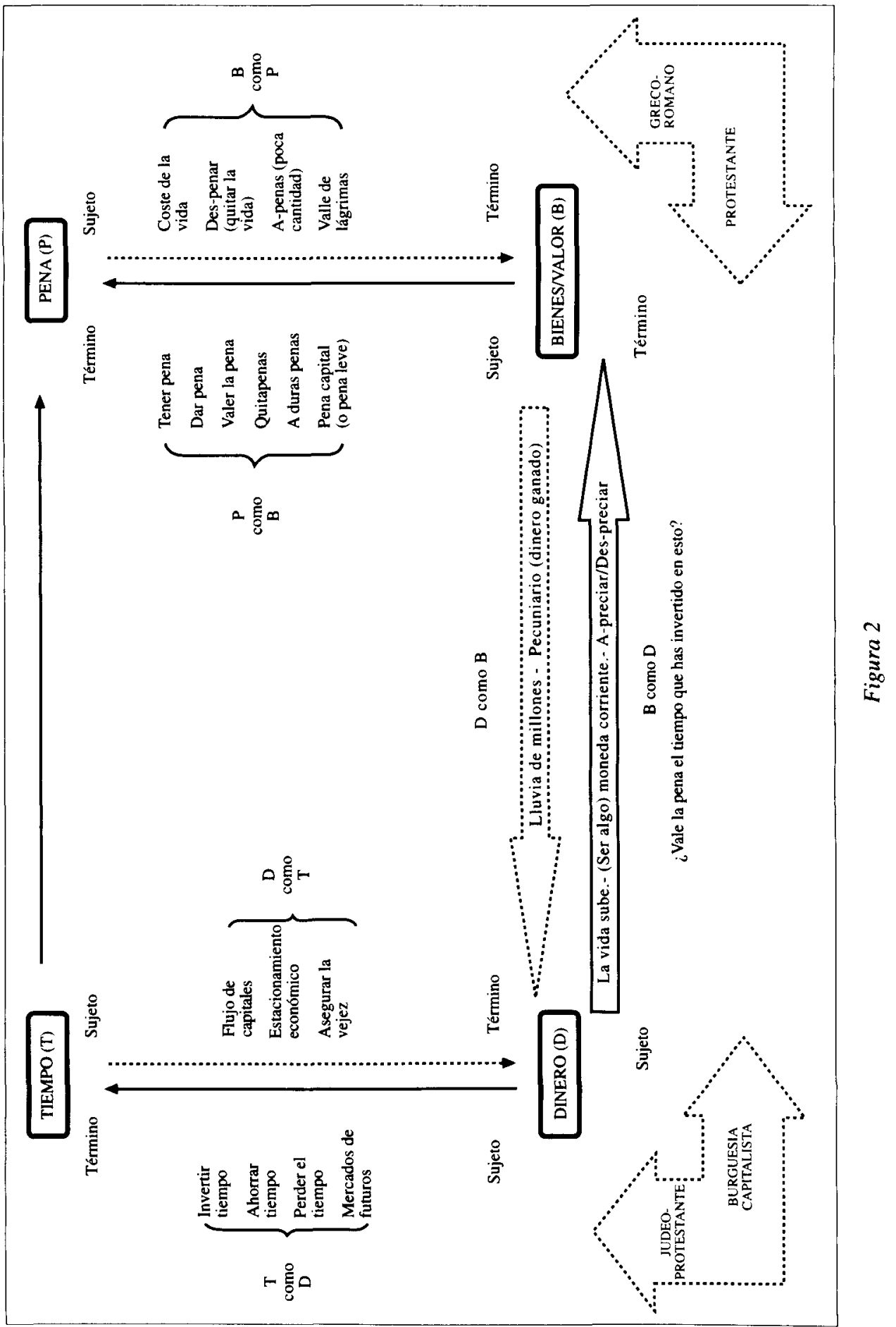


como la judeo-cristiana, entiende el tiempo como una flecha unidireccional en progreso constante puede ponerse ese tiempo en correlación con el dinero; pero, por otra parte, sólo desde otra cultura que, como la de la burguesía moderna, hace del dinero un equivalente universal de valor puede ese dinero asimilarse a una línea recta continua susceptible de asociarse con aquel tiempo lineal. Desde otra concepción del tiempo, como puede ser la circular en las sociedades agrícolas, esa analogía es imposible, o bien -de establecerse- daría lugar a una percepción del dinero como algo que, al irse acumulando, vuelve cíclicamente a su valor inicial. $\mathrm{E}$ inversamente, desde unas culturas que desarrollan distintas series numéricas para enumerar y valorar distintas clases de bienes (y que carecen, por tanto, de un equivalente universal de valor), unas culturas que tienen monedas distintas para clases distintas de objetos, la analogía entre dinero (es decir, distintos dineros) y tiempo proyectaría sobre éste la multiplicidad de aquél, y daría lugar -como, de hecho, da- a la posibilidad de tiempos distintos para las distintas clases de objetos. Sólo la conjunción de ambas culturas, judeo-cristiana y burguesa, en las mentalidades protestante e ilustrada abrirá la posibilidad de una analogía coherente entre dinero y tiempo desde la cual lleguen a poder instituirse metáforas como ese 'tiempo invertido'. Esas instituciones básicas en nuestra sociedad que son el Tiempo y el Dinero quedan así reflejadas, pero también reforzadas en su internalización, cada vez que se habla -y se oye hablar- de 'invertir tiempo'.

Una hermenéutica paralela para la expresión 'valer la pena' nos remite a la consideración de la pena como un bien, algo que se posee ('dar pena', 'quitapenas'), algo, por tanto, susceptible de valor y cálculo ('mucha/poca pena', 'apenas', 'le cayeron 10 años de pena'). En griego, $\pi$ oı $v$ ' (de donde, en latín, poena) tiene el significado de multa o penalización (la cantidad a pagar por un rescate, por ejemplo). Aquí sería la conjunción de esa pena greco-latina, mensurable, con la valoración positiva (un 'bien') del sacrificio que hace el cristianismo la que dotaría de sentido a ese 'valer la pena'. Esta expresión carecería de sentido desde otra concepción de la pena, por ejemplo, desde una concepción de la pena como algo carente de valor o como algo que no se puede tener sino que más bien es ella la que le tiene a uno, como en la copla popular que recoge A. Machado: "Tengo una pena, una pena, / que casi puedo decir / que yo no tengo la pena: / la pena me tiene a mí». Al invertir el sentido de este grupo de metáforas, la consideración de un bien (como 'la vida') en términos de pena daría lugar a metáforas como las de la derecha de la Figura 2.

Instituidos así, por una parte, el tiempo en términos de dinero ( $T$ como $\mathrm{D}$ ) y, por otra, la pena en términos de un bien (P como B), sólo falta que los campos de ambos sujetos metafóricos (D y B) se asimilen mediante una analogía también instituida $(\mathrm{D} \approx \mathrm{B})$ para que ambos campos lleguen a identificarse $(\mathrm{D}=$ B) y pueda tener sentido entender $T$ como $P$, es decir, el tiempo (invertido) como una pena (que vale). Pero ciertamente la analogía entre bienes/valores y dinero parece bien establecida en las sociedades modernas ${ }^{18}$, como prueban metáforas

18 Dicho de otro modo, la necedad de que habla Machado es entre nosotros necedad social: "iQuién fuera diamante puro! / -dijo un pepino maduro. / Todo necio / confunde valor y precio". 
tan consolidadas como 'la vida sube' (de nuevo, 'el precio de la vida sube' sería un pleonasmo pues la vida es su precio) o 'apreciar/despreciar' (donde la valía que se reconoce o se niega se dice en términos monetarios). Así, esa susceptibilidad de la pena para devenir objeto de valor y cálculo es la que hace posible asimilarla a un tiempo percibido en términos de dinero (expresión también de valor y objeto de cálculo), de modo que la metáfora "valer la pena el tiempo invertido' (metáfora ahora de segundo orden, pues en ella sujeto y término son a su vez conceptos metafóricos) resulte una expresión no sólo posible sino natural y evidente. Esa naturalidad con que tal expresión se emite y se entiende señala precisamente el proceso de naturalización ideológica que han sufrido todos los contextos socio-culturales mencionados, sin los cuales una expresión así no sería posible ni, menos aún, tan trivial y opaca como lo era para aquel escéptico interpelante (que, con todo, se despidió asegurando que valió la pena haber puesto durante un rato su expresión entre comillas, aunque nada me dijo del resto del tiempo perdido).

\section{LA DOBLE INSTITUCIONALIZACIÓN DE LOS CONCEPTOS CIENTÍFICOS}

A esta institucionalización de los términos y expresiones del lenguaje ordinario, se añade -en el caso de los conceptos científicos- una segunda institucionalización, ésta ya consciente, sistemática y corporativa. Buena parte del trabajo científico consiste, efectivamente, en depurar -escrupulosa y metódicamenteaquellas metáforas instituyentes que estuvieron en el origen de una hipótesis o concepto nuevos de toda la ganga de adherencias simbólicas, tomadas del lenguaje común o del de alguna otra disciplina científica. Se ha llegado incluso a afirmar que la única diferencia entre el texto científico y el literario se cifra en la cantidad de recursos retóricos puestos corporativamente en juego para impedir aflorar toda la actividad social en que se sustentan, actividad social que aquí se nos ha manifestado en la construcción metafórica de los conceptos. La institucionalización del concepto así reelaborado por la comunidad científica se refuerza, además, constantemente a través del sistema educativo, en el que el significado de los conceptos científicos nunca se presenta genéticamente (es decir, recorriendo sus diferentes reelaboraciones históricas, todas metafóricas) sino mediante puras -0 sea, depuradas- definiciones formales.

En esta operación orwelliana de reescritura incesante ${ }^{19}$, el sentido simbólico de la metáfora matriz se vacía en el mero significado formal y, en un segundo momento, éste significado se vacía a su vez -tanto más cuanto la disciplina científica en cuestión más se acerca al ideal matemático de todas las ciencias- en el puro significante, en expresiones que no tienen otro sentido ni significado que el que les prestan las reglas del juego formal en el que se inscriben, es decir, el que les atribuye la sintaxis que articula su funcionamiento operacional. Lo cual queda

${ }_{19}$ Véanse M. Serres (1967), S. Woolgar (1991), B. Latour (1992) o D. Locke (1992). 
de manifiesto paradigmáticamente en la institucionalización de los conceptos matemáticos, como quiere mostrar el siguiente ejemplo.

\subsection{La $\sqrt[6]{ }$ ': un concepto agrícola}

Seguramente nunca hasta este momento el lector, convenientemente socializado en ciertas matemáticas, se habrá parado a pensar que la 'raíz cuadrada' es un concepto metafórico. De una raíz, puede predicarse con propiedad que sea profunda, comestible o -en todo caso, y ya trasladándonos del ámbito botánico al geométrico- fractal, pero ¿cuadrada? Aquí conviene hacer una precisión: la expresión 'raíz cuadrada' es una abreviatura de la expresión original 'raíz del cuadrado', por lo que es en ésta en la que nos centraremos. En los momentos en que tal concepto es aún una metáfora viva, la comunidad matemática aún no ha canonizado una expresión entre todas las que circulan. Aún en el llamado Renacimiento, el portugués Pero Nunes habla de «lado criando cuadrado», mientras que para el italiano Bombelli se trata de «el lado de un número no cuadrado, el cual es imposible de poder nombrar, pero se dice Radice sorda, o bien indiscreta, como sabemos». En la cita de Bombelli se manifiesta ejemplarmente la situación que teorizábamos en el $\$ 4.2$., cuando el científico focaliza metafóricamente en un sujeto el concepto que aportará la solución a un problema, solución que aún le resulta «imposible de poder nombrar». Y, como un bricoleur, al decir de Lévi-Strauss, va ensayando con términos que recoge del lenguaje corriente: 'radice sorda', 'radice indiscreta', 'lado criando cuadrado'... Es precisamente esta ebullición instituyente la que nos pone en la pista de las connotaciones y evocaciones que una particular visión del mundo pone en juego para construir el concepto. El término 'sordo' hace referencia al hecho de que -aún- no puede nombrarse o decirse ni, por tanto, oírse. Pero términos como 'radice' o 'radix' o el de 'criar' en Nunes indican que se está estableciendo más o menos inconscientemente una semejanza entre un campo geométrico (en el que hay objetos como 'lados' y 'cuadrados') y otro biológico (en el que hay 'raíces' y 'crianzas'). Esta semejanza es la que hace posible la analogía:

$$
\frac{\text { Raíz }}{\text { Planta }}=\frac{\text { Lado }}{\text { Cuadrado }}
$$

Es decir, la relación de un lado con su cuadrado (o sea, con el cuadrado que lo tiene por lado) es como la relación de una raíz con la planta a la que sustenta. De esta analogía se sigue la metáfora 'raíz del cuadrado' al tomar la raíz como sujeto (sobre el que se focaliza el problema de nombrar el lado de un cuadrado dado) y el cuadrado como término; operación simbólica que acabará institucionalizándose en el término ya técnico de 'raíz'. La conexión de la metáfora con el concepto actual puede hacerse restableciendo todas las elipsis que ha ido introduciendo el trabajo de depuración y olvido que ha llevado de la primera al segundo: calcular $\sqrt{9}$ (lo que seguimos expresando como extraer la raíz de 9) es hallar la longitud del lado capaz de criar o engendrar un cuadrado de superficie 9. Tal 
solución o raíz es 3 porque el cuadrado -que se engendra a partir- de 3 es 9 (o, más depurado aún de significados adheridos, $3^{2}=9$ ).

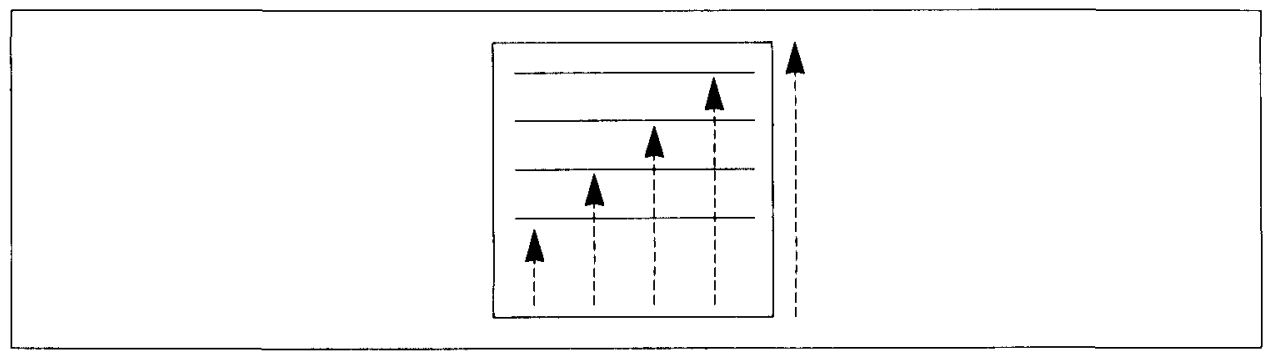

Figura 3

La biologización de las formas geométricas no parece en los textos matemáticos medievales y renacentistas una operación metafórica sino literal. Para unas sociedades aún fundamentalmente agrícolas y, en buena medida, animistas, nada más propio que percibir un segmento como algo dotado de vitalidad y potencia propia, capaz de engendrar y alimentar o criar algo que crece nutriéndose de él; y recíprocamente, no menos natural es concebir ese algo (el cuadrado) enraizado en un suelo (el lado) que lo nutre y aporta su sustancia, posibilitando su despliegue para ir haciéndose espacio (Figura 3). Pero tampoco ahora estamos haciendo poesía, o al menos no más de la que hacían los matemáticos de la época cuando hacían matemáticas. Los términos nuevos empleados en la descripción anterior son usados como términos matemáticos en los textos griegos o en sus traducciones latinas, que es donde se inspiran los matemáticos renacentistas. Así, Euclides habla de la 'potencia' ( $\delta v$ v $\alpha \mu l \zeta$ ) del lado para referirse al cuadrado, término que en los textos latinos se traduce por substantia. De modo que hablar de cuadrados que extraen su sustento o sustancia de una raíz que les presta su potencia no es - para esas sociedades- ninguna figura poética, sino una expresión literal, es decir, una expresión propiamente matemática.

Pero la lógica que impone la metáfora a la construcción de conceptos y resolución de problemas científicos no se limita al momento instituyente de aquélla sino que seguirá gobernando la lógica de la investigación durante todo el tiempo que cierta tradición de investigación -como la del álgebra durante casi dos milenios- la mantenga como concepto. Así, la toma de conciencia -propia de la sensibilidad manierista- de los recursos retóricos del lenguaje y, en particular, de la metáfora como generadora de nuevos significados (véase, por ejemplo, la obra de Rabelais), será la que permita poner entre comillas una expresión como 'raíz cuadrada', es decir, ver en ella lo que hay de metáfora, de ficción, en lugar de tomarla como una expresión natural. Sólo desde esa conciencia del carácter metafórico de la raíz cuadrada podrá la ficción prolongarse más allá de sí misma y conceder sentido -para los matemáticos manieristas- a una expresión como 'raíz cuadrada de un número negativo', que es por completo incoherente con la 
asociación entre 'lado' y 'raíz' que proponía la analogía latente bajo la metáfora original ¿Cómo puede -si no es por ficción, convenio o artificio- un lado/raíz engendrar, no un cuadrado/planta, sino la falta del mismo?. La misma conciencia de que la ficción y la metáfora engendran realidades nuevas es la que logrará, en pintura, que trucos como el trampantojo y la perspectiva resulten realistas y, en matemáticas, que los 'números ficticios' se tomen como verdaderos números. Y serán de nuevo razones -0 sinrazones- culturales las que, con el neo-realismo que sucederá a su vez al barroco, exigirán tomar las metáforas al pie de la letra, por lo que volverán a quedar sin sentido esos números 'imaginarios', 'ficticios' o 'absurdos' ${ }^{20}$. La historia de la operación matemática 'raíz cuadrada' exige así -para poder ser entendida en toda su profundidad- pensarse como la historia de una operación metafórica, sujeta por tanto a los mismos avatares que irán sufriendo los demás lenguajes (literario, pictórico, filosófico...) -avatares que, por cierto, en nada se parecen a ese progreso acumulativo del saber con que suele falsearse la historia de las ciencias.

El sujeto de la metáfora, ése en el que se focaliza la resolución de los problemas científicos, no es ese objeto encastrado en el aparato ideal de la lengua que habitualmente manejan los lingüistas, sino un sujeto histórico y social ${ }^{21}$. Y, paralelamente, las soluciones y conceptualizaciones que van adoptando los problemas científicos son también constitutivamente históricas y sociales. Así, buena parte de lo que se tiene como historia externa de la ciencia es historia interna. La evolución del álgebra, por ejemplo, es indisociable de la evolución de las relaciones que mantiene el hombre con las plantas y la tierra, que irán modificando las connotaciones que el sujeto metafórico 'raíz' traslade en cada momento y lugar al término algebraico correspondiente. Para el hombre griego, el medieval e incluso el renacentista, arraigados todos ellos a la tierra, es natural percibir un cuadrado como algo también enraizado en el suelo, del cual extrae -como casi todo en su mundo- su sustento o sustancia. Para él la expresión 'raíz del cuadrado' es más literal que metafórica. Esa expresión empieza a percibirse como metafórica cuando, con el Barroco, el centro de gravedad de la vida social se desplace del campo a las ciudades. Las condiciones para que los cuadrados se desarraiguen sólo se darán con la violencia de ese desarraigo general que supondrá el paso del orden medieval al orden burgués, donde ya no será la tierra $-\mathrm{y}$, con ella, los bienes también raices, como los cuadrados- la principal generadora de valor y riqueza.

20 'Imaginarios' les llamó Descartes «porque sólo existen en la imaginación», a diferencia de los 'números reales', que sí existen en la realidad. Leibniz, por su parte, los calificó de 'centauros ontológicos', pues están «a medio camino entre el ser y el no ser». Las metáforas matemáticas podrían multiplicarse, aunque la que acabó institucionalizándose fue la cartesiana y hoy no se calcula con 'números centaúricos'.

${ }^{21}$ Como es sabido, el concepto 'texto' es un concepto metafórico construido sobre el sujeto 'tejido' (de ahí la urdimbre de un texto, el hilo de su argumento, el hilvanar frases. etc.); pero los sucesivos cambios en el modo de tejer (artesanía doméstica femenina, actividad gremial, producción industrial, etc) y en la estimación social de esa actividad irán proyectando sobre el término 'texto' -y sobre sus usos y modos de análisis- las variaciones sociales e históricas que van experimentado los 'tejidos' (véase la Introducción de J.A. Millán y S. Narotzky a G. Lakoff y M. Johnson, 1991). 
Se impone aquí una observación: la metáfora es mucho más que la analogía, y el análisis metafórico alcanza más calado que el basado en la consideración de las teorías científicas como modelos analógicos, al modo de los emprendidos por M. Black o M. Hess. Como habíamos señalado, la analogía es reversible, la metáfora no. La metáfora, al estar orientada, condiciona el sentido de los significados que transporta. Por ello, el establecimiento de una analogía en un momento determinado no implica la emergencia de todas las metáforas que esa analogía hace posibles. Una vez más, son factores sociales los que seleccionan qué metáforas, de entre las permitidas por esa analogía, emergerán efectivamente. Así, la percepción de las figuras geométricas en términos vegetales que, como hemos visto, se da en ciertas épocas históricas no conlleva la percepción inversa, es decir, la de los vegetales y seres animados en general en términos geométricos. Para que una raíz pueda llegar a pensarse como cuadrada habrá de invertirse la perspectiva, de modo que el mundo de la vida $-\mathrm{y}$, en particular, el de las plantas- llegue a poder pensarse more geometrico, lo cual no ocurrirá hasta la época de Galileo, en la que ya sí es pensable una naturaleza escrita en lenguaje matemático. El cubismo no será sino la apoteosis de ese racionalismo para el que ya sí resultan naturales los pechos cónicos, los bodegones con frutas cúbicas y las raíces cuadradas.

\subsection{El cierre del círculo metafórico: de vuelta al lenguaje ordinario}

La circulación de metáforas entre las disciplinas científicas es uno de los recursos heurísticos más frecuentes y poderosos ${ }^{22}$. Sin embargo, cuando esta circulación se orienta hacia formas de discurso a las que se concede un 'nivel de cientificidad' más bajo que el de las ciencias 'duras' -como es el caso de las ciencias sociales, la filosofía y el lenguaje ordinario-, a la traslación de significados característica de toda actividad metafórica se añade la pretensión de importar el prestigio social de que gozan aquellas ciencias en las sociedades modernas. El objeto de la metáfora, como hemos visto, es poder alojar en el lenguaje un problema o acontecimiento que por su oscuridad es aún inefable, usando para ello el conocimiento que se tiene de otro ámbito. Pero, en los casos citados, la traslación de significados no sigue este camino sino el contrario: en lugar de intentar nombrar lo opaco y oscuro mediante lo evidente y claro, son los tópicos y conceptos comunes los que se formulan en los términos más pedantes y esotéricos. De vehículo de conocimiento, la metáfora pasa a serlo de ocultación e ininteligibilidad. En esto, Sokal (1997) ha acertado a concentrar en la filosofía francesa la denuncia que ya Andreski (1973) hiciera extensiva a todas las ciencias sociales (psicología, sociología, antropología, economía, etc.) sin distinción de lenguas, de disciplinas ni de orillas del océano (Merton, Parsons, Lévi-Strauss...).

${ }^{22}$ Véase, por ejemplo, I. Stengers (1987), L. Preta (1993), K. Hayles (1993) o toda la obra de M. Serres. 
En ocasiones, con la aparente pretensión de aportar rigor y precisión, se consigue un grado de imprecisión que raya en el absurdo: «un problema de 'proporciones inmensas'" contradice, con su falta de medida, la mensurabilidad que exige el concepto matemático de proporción. Otro tanto ocurre con esas 'inmensas mayorías', que para ser mayorías han debido previamente poder medirse. Así mismo, mal puede 'sobredimensionarse un problema' cuando, precisamente por ser un problema, no le es aplicable en ningún sentido el concepto también matemático de 'dimensión'. La lista sería interminable: 'parámetros sociales', 'coeficientes de peligrosidad', 'coordenadas políticas', 'niveles de desarrollo', 'despejar la incógnita (sobre una candidatura)', 'ser funcional', 'sumar voluntades', 'factores sociales', 'hombre medio' 23 , 'ponderar un asunto', 'gradientes de tensión (laboral o política)', 'incrementos culturales'...

Con frecuencia, esas metáforas instituidas proyectan sobre lo social categorías planas y mecánicas que tienden a borrar todo rastro de heterogeneidad y antagonismo. Toda la jerga funcionalista y neo-funcionalista, enriquecida hoy con los aportes de la informática, es un buen ejemplo, pero también lo son expresiones aún más generalizadas. Conceptos como 'segmentación social' o 'sectores sociales (o productivos, o culturales)' reducen la percepción de lo social a la imagen de una línea, susceptible de segmentarse, o de un círculo, divisible en sectores circulares. Ese 'conjunto social' al que se llama 'sociedad' incorpora así todas las propiedades específicas de esos objetos matemáticos que son la recta de los números reales y el círculo definido en $\mathfrak{R}^{2}$, como son el estar constituidos por puntos homogéneos, el que a cada uno de ellos se les pueda atribuir una magnitud ( $\mathrm{y}$, por tanto, sumar, restar, etc.), el que se encuentren totalmente ordenados, el constituir conjuntos densos y compactos, etc.

Sin embargo, esto no parece ser óbice para superponer a esas metáforas matemáticas otras metáforas mecánicas totalmente incongruentes con ellas. Hablar del «peso específico de un sector social» no sólo supone pensar lo social como un fragmento de superficie circular sino atribuir a esa superficie una propiedad física como el 'peso específico' que no puede tener. Sin embargo, estas metáforas imposibles (imposibles como operaciones conceptuales, aunque bien posibles -y aún habituales- como operaciones ideológicas) son moneda corriente: «ciertos 'sectores (o segmentos) sociales' han gravitado hacia posiciones extremas», el «peso de otros 'sectores (o segmentos) sociales' otorga una mayoría aplastante», la «inercia de ciertos 'parámetros políticos' produce un incremento negativo en los 'niveles de confianza' de los 'sectores deprimidos'»...

La incorporación metafórica de conceptos científicos al lenguaje corriente -a través de esa jerga común a políticos, periodistas, empresarios, sindicalistas, economistas, miembros de la administración y científicos sociales- resulta especialmente preocupante por cuanto, lejos de aportar mayor rigor conceptual o expresivo, empobrece un lenguaje capaz de un conocimiento mucho más rico y

23 Sobre el lenguaje de la estadística y el del Estado como «hechos que se construyen entre sí», en un incesante préstamo recíproco de metáforas, puede verse A. Desrosières $(1993,1995)$ o C. Javeau, «De l'homme moyen à la moyenne des hommes: l'illusion statistique dans les sciences sociales», en V. De Coorebyter (1994). 
matizado que el que se transporta (U. Pörksen, 1995). Las consecuencias pueden ser funestas para las propias ciencias, pues el lenguaje ordinario, del que ellas mismas extrajeron sus conceptos, y ahora empobrecido por ellas, es el mismo del que habrán de seguir extrayendo sus conceptos en el futuro.

\subsection{La reflexividad en la conceptualización sociológica de los conflictos sociales}

La construcción y uso de conceptos sociológicos se mueve entre dos extremos. Por un lado, la traslación metafórica de conceptos elaborados por las ciencias matemáticas y naturales, por otro, la incorporación ingenua de términos del lenguaje ordinario y, particularmente, de las jergas de ciertos grupos sociales (empresariales, políticos, burocrático-administrativos) con los que el sociólogo mantiene especial comercio, y no sólo linguíistico. En el primer caso, lo que se gana en supuesto prestigio y aparente cientificidad se pierde, como acabamos de ver, en rigor y coherencia conceptual y en claridad expresiva; en el segundo, se incorporan acríticamente al lenguaje de la disciplina los valores, intereses y visión del mundo propios de esos grupos particulares, lo que tiene importantes efectos a la hora de estudiar, por ejemplo, situaciones de conflicto en las que están implicados algunos de esos grupos. Pero en ninguno de ambos casos suele procederse arese trabajo de depuración y refinamiento que hace de la metáfora un concepto preciso e integrado en un cuerpo teórico ${ }^{24}$ coherente y con capacidad explicativa o interpretativa. Si bien esto hace de muchos conceptos sociológicos fácil diana para un análisis socio-metafórico como el aquí ensayado, también lleva a este tipo de discursos a moverse entre el despropósito teórico, la complicidad ideológica con ciertos intereses de grupo o de clase, y un oscurantismo sólo proporcional a la trivialidad de sus conclusiones.

Esta situación, decíamos, cobra un relieve especial cuando el sociólogo estudia conflictos sociales en los que aparecen implicados grupos de cuya lenguaje específico $-\mathrm{y}$, por tanto, de sus intereses y presupuestos- toma el sociológico prestamos metafóricos. Así, en los conflictos entre la administración y la industria, por una parte, y colectivos ecologistas y la gente afectada por un problema medioambiental, por otra, los análisis en términos de 'impacto social' (de una tecnología o de la ciencia, en general) asumen la perspectiva de una de las partes, de la que el sociólogo resulta aliado inconsciente; lo que no quita para que, en estos casos, la propia comunidad científica sea la primera en recurrir -por boca de sus portavoces cualificados- a metáforas cuya impropiedad habitualmente denuncia -ya reivindicando 'los intereses de la sociedad en su conjunto', ya denunciando 'la oleada de irracionalidad' o la amenaza de 'invasión por las pseudociencias' (E. Lizcano, 1996).

${ }^{24}$ Ciertamente, no pueden decirse dos palabras seguidas sin que nos asalten las metáforas. Ésta del 'cuerpo teórico' pertenece a esa familia formada por 'cuerpos sociales', 'cuerpos electorales' y otros 'cuerpos (más o menos) místicos' que tienden a naturalizar el campo analógico respectivo (epistemológico, social, político o religioso). 
La beligerancia de la terminología sociológica resalta en especial en los estudios sobre el desarrollo, cuya conceptualización dominante exhibe todo un rosario de metáforas bélicas que articulan todo el análisis 25 : 'estrategias de desarrollo', 'ejes de actuación', 'políticas de intervención', 'actividades poco productivas con un alto nivel de mortandad', 'estrangulamientos al desarrollo', 'lucha contra los obstáculos a la modernización', 'pérdida de posiciones de ciertos sectores productivos', 'resistencia de ciertos frentes del sector informal'... La progresiva consciencia de que, en todo conflicto social, una de las batallas principales se dirime en torno a imponer al oponente el uso de las metáforas propias, y con ellas la propia visión del conflicto y de su solución, está llevando en los últimos años a ciertos movimientos sociales, cada vez más numerosos en el llamado Tercer Mundo, a abandonar el lenguaje del desarrollo y la modernización: «Lo que ahora debemos desafiar es la idea misma del desarrollo: la adopción de un emblema universal para la transformación social de muy diversos modos de vida, que expropia la dignidad de la gente, su confianza en sí misma, sus sueños propios, y debilita sus capacidades y destrezas» (G. Esteva, 1995: 53 ).

Allí donde las formas de producción y de vida (y de hablar) siguen siendo básicamente las tradicionales, las metáforas $-\mathrm{y}$, por tanto, los intereses y objetivos- de las ciencias duras, las de las ciencias sociales y las de las tecnoburocracia a menudo se perciben como metáforas solidarias entre sí, cuya potencia instituyente se opone a las metáforas locales ya instituidas y transmitidas por la tradición a través de leyendas, fórmulas cristalizadas, refranes, recitaciones orales, etc. (J. D. van der Ploeg, 1990). El antagonismo de las metáforas en juego se ve reforzado en aquellas ocasiones en las que los espacios físicos desde los que se construyen las respectivas metáforas son espacios enfrentados, como pueden serlo el mar y la tierra ${ }^{26}$. Así, conceptos como 'cultivos marinos', 'agentes de extensión pesquera' (por analogía con los 'agentes de extensión agraria'), 'aguas territoriales', 'sector marisquero', 'explotación marina', 'bancos de peces'... manifiestan la percepción del 'mar' en términos de 'tierra' (y, además, la de la tierra como tierra de conquista), como es propio de quienes viven en la tierra y en la tierra tienen los despachos en los que trabajan. A quienes viven la mayor parte del tiempo en el mar y tienen en él su lugar de trabajo, esas metáforas, por muy instituidas que estén como conceptos para otros, son metáforas vivas, que a menudo se perciben como impropias, cuando no literalmente opuestas. En la 'mesa de negociaciones' o en los cursos de formación para mariscadoras, más que expresarse el conflicto, ya se ha resuelto: una de las partes en conflicto ha traído al hombre y a la mujer de mar, literalmente, a su terreno:

${ }^{25}$ Este ejemplo y el siguiente están tomados de sendos trabajos de investigación realizados por alumnos del Curso de doctorado que imparto en la UNED sobre «Ciencia, metáfora y sociedad». Del primero, debido a Angel Rivero, puede verse un resumen en "Territorio versus planificación: metáforas del desarrollo", Archipiélago, 34-35 (1998): 108-115. El segundo es un estudio aún en curso a cargo de Mercedes Fernández Gestido, un avance del cual fue objeto de la comunicación "Conocimiento científico y saber popular: un conflicto sobre la mar y los peces», VI Congreso Español de Sociología, La Coruña, 1988.

${ }^{26}$ Véase nota anterior. 
ése en el que ya sólo tienen sentido ciertas metáforas y, por tanto, ciertos modo de vida y concepciones del mundo. La oposición, a veces con violencia física, entre mariscadoras, mariscadores y pescadores de bajura del litoral gallego y la administración de la Xunta se expresa -y, en buena medida, se dirime- en torno a metáforas como las anteriores. Y los compromisos de los científicos implicados (sean oceanógrafos o biólogos, sean economistas o científicos sociales) se expresan -y se establecen- asimismo en la coherencia o incoherencia de sus conceptos metafóricos con las metáforas claves del lenguaje de cada una de las partes en conflicto.

Son numerosas las ocasiones en que la alteridad del objeto de estudio obliga al investigador social riguroso a volverse sobre su propio sistema conceptual, para lo que un análisis socio-metafórico como el propuesto puede ofrecer también una herramienta reflexiva.

\section{Corolario 1: La ciencia, literatura acorazada}

De aquella tajante escisión entre expresiones propias y figuradas, propia de la tradición heredada, se siguen, en particular, los distintos criterios de demarcación aún vigentes, sean los que separan a las ciencias de las supersticiones o seudo-ciencias, o a las ciencias duras de las blandas, o a la propia ciencia como un todo de la literatura. Incluso quienes, como el primer Bachelard, conceden cierto papel a las metáforas en la actividad científica, siquiera sólo sea en ese momento poético de la ciencia que es la formulación de hipótesis y conjeturas, consideran que esas irrupciones metafóricas son un obstáculo posterior para el desarrollo de la ciencia, un obstáculo que, como tal, debe ser cuanto antes perseguido y reducido. Momento en el cual puede volver a hablarse propiamente de ciencia. Sin embargo, la relativización y la difuminación de la distinción entre significados propios y significados metafóricos que hemos venido observando, conlleva también la relativización y difuminación de los diferentes ámbitos de demarcación mencionados. El análisis socio-metafórico parece llevarnos a concluir efectivamente que la principal -si no la única- diferencia entre ciencias físicas y sociales, y, más aún, entre el lenguaje de las ciencias en general y el lenguaje literario, o incluso el propio lenguaje corriente y moliente, está en el grado de acorazamiento frente el análisis que han ido adquiriendo sus metáforas, en la resistencia institucional que los conceptos científicos son capaces de oponer a su deconstrucción en tanto que conceptos metafóricos y sociales.

\section{Corolario 2: Imposturas científicas (o las matemáticas orwellianas de Sokal)}

Terminemos haciendo terciar este método en una polémica bien actual, la del asunto Sokal. No le falta razón a éste cuando arremete contra filósofos y sociólogos que usan a su antojo conceptos científicos sin saber de lo que hablan. No es en ese terreno en el polemizaremos con él, sino en el suyo propio: en el uso que él mismo hace de los conceptos científicos sin saber tampoco de lo que habla.

En su reciente denuncia de las Imposturas intelectuales que, a su juicio, 
caracterizan a la posmodernidad, compara a Lacan con Woody Allen, pues le parece «preocupante ver nuestro órgano eréctil identificado con la raíz de menos uno» (A. Sokal y J. Bricmont, 1997: 32). Efectivamente, Lacan, en sus Écrits afirma que «el órgano eréctil viene a simbolizar el lugar del gozo (...), en tanto que parte faltante de la imagen deseada: por eso es igualable a la raíz de menos uno". Nada tiene eso que ver, por supuesto, con ese concepto de 'unidad imaginaria' con que lo enfrenta Sokal, ése con el que el álgebra moderna redefine la 'raíz de menos uno', ése que alguien le enseñó a nuestro físico algún día, en pleno auge de la moda bourbakista, en una clase de matemáticas y en el que se agota su conocimiento del asunto. Esa ignorancia matemática es precisamente la que le permite afirmar que nos encontramos ante una metaforización abusiva, ante unos "cálculos que son pura fantasía». Al margen de que pueda hablarse con propiedad de una fantasía que sea pura, si Sokal hubiera sabido que ese mismo calificativo fue el que empleo Descartes, no para los cálculos de Lacan, sino para los cálculos de Cardano y Bombelli con números 'imaginarios', se habría ahorrado esa exhibición de ignorancia matemática. Efectivamente, el científico puede trabajar con los conceptos de su disciplina en la medida en que ignora su constitución interna, es decir, metafórica, pero la utilidad que le aporta la ignorancia sobre el contenido de esas cajas negras con las que trabaja, no sólo no disculpa tal ignorancia sino que la revela constitutiva de su propio trabajo.

No cabe duda de que Lacan -y él mismo lo dice- extrapola metafóricamente un concepto matemático para conceptualizar un concepto psicológico, el del 'deseo'. Pero, como ya vimos ( $\$ 6.1$ ), ese concepto matemático era a su vez una extrapolación metafórica, ni más ni menos abusiva, de una concepción biológica. Como ponen de manifiesto más de dos milenios de historia de las matemáticas (para quien no crea que éstas nacieron el día que se las enseñaron en clase), en la institucionalización del concepto ' $\sqrt{-1}$ ' los matemáticos lidian durante siglos -y en cada uno de una manera diferente- con el problema de hacer coherentes dos metáforas antagónicas. Por un lado, el problema de la $\sqrt{ }$, , es decir, el problema de hallar 'aquello que está en la raíz de una potencia' (la potencia cuadrada: $\delta v ́ v \alpha \mu t \varsigma$ ), aquello que la origina. Por otro, el problema del ' -1 ', es decir, en términos de Diofanto (que no era poeta ni psicoanalista), el problema de la 'ausencia' o 'falta' $(\lambda \varepsilon t \pi \sigma \zeta \zeta)$. La conjunción de ambos problemas en el problema de atribuir significado a ' $\sqrt{-1}$ ' podría enunciarse literalmente -es decir, matemáticamente- como el problema de hallar 'aquello que está en la raíz de una potencia que, a su vez, consiste en una falta'. Que la 'potencia' se asocie con el deseo y que la 'raíz' de éste se busque en una 'falta' (del objeto deseado) no parece descabellado ${ }^{27}$.

\footnotetext{
${ }^{27}$ Este tipo de análisis podría extendenderse a las restantes evidencias de Sokal. Por ejemplo, sólo se puede afirmar que 'cero' es «forzosamente [un número] racional» (p. 31) cuando se ignora que 'cero' no era ni siquiera un número para Euclides (al que acaso Sokal excluya de la nómina de los matemáticos, pese a ser el padre de la disciplina) y que su status como número ha sido discutido por los mejores matemáticos hasta épocas muy recientes. De hecho, su actual definición como "cardinal del conjunto vacío', es decir, como «número de elementos que contiene un conjunto que no contiene ningún elemento" dista mucho de ser forzosamente evidente. A no ser que la fuerza que hace de 'cero' un número sea la fuerza del acuerdo social entre los matemáticos de considerarlo como tal pese a la evidencia en contrario, pero ésa es precisamente la conclusión que más irrita a Sokal.
} 
Podemos seguir a Sokal cuando denuncia el uso de las matemáticas y la jerga científica para oscurecer el asunto, siempre que su lista abarque tanto a ciertos filósofos como a numerosos científicos (médicos, economistas, estadísticos, etc.), tanto a posmodernos como a modernos realistas ilustrados con los que parece alinearse. Podríamos haberle seguido incluso si, analizando efectivamente la metáfora lacaniana, hubiera observado esa falta de rigor en su trabajo de traslación metafórica que le permite alterar los términos de la proporción analógica. Pero no podemos seguirle en el rotundo desconocimiento de las matemáticas que le lleva a afirmar que «los términos 'irracional' e 'imaginario' no tienen nada que ver con su significación ordinaria o filosófica» (p. 31), pues es precisamente de su significación en el lenguaje ordinario de donde extraen no sólo su nombre sino capacidad -o no- para resolver problemas y el modo en que los resuelven, e incluso su significado y su funcionamiento actuales.

Los conceptos científicos no nacen ya armados, como Atenea de la cabeza de Zeus, sino que lo hacen de ese hervidero de metáforas latentes que es el imaginario social. Y ningún científico ni seudofilósofo puede reclamar como propiedad corporativa lo que tomó del acervo linguístico común -aunque lo ignore- y a ese acervo sigue perteneciendo ${ }^{28}$. Cuando se toma escuetamente la última reconstrucción teórica de un concepto científico y se pone en lugar de toda la compleja red de elaboraciones y reelaboraciones que de ese concepto han ido tejiendo las diferentes sensibilidades sociales a lo largo de la historia, entonces sí debe hablarse literalmente de impostura, y no sólo intelectual.

\section{BIBLIOGRAFÍA CITADA}

ANDRESKI, Stanislav (1973): Las ciencias sociales como forma de brujeria, Taurus, Madrid. BLACK, Max (1966): Modelos y metáforas, Tecnos, Madrid.

BLoor, David (1998): Conocimiento e imaginario social, Gedisa, Barcelona.

CHENG, François (1994): Vacío y plenitud, Siruela, Madrid.

COOREBYTER, Vicent de (1994): Rhétoriques de la science, PUF, París.

DERRIDA, Jacques (1989a): «La mitología blanca. La metáfora en el texto filosófico», en Márgenes de la filosofía, Cátedra, Madrid.

- (1989b): La deconstrucción en las fronteras de la filosofía. La retirada de la metáfo$r a$, Paidos, Barcelona.

DesRosières, Alain (1993): La politique des grandes nombres, La Découverte, París.

- (1995), «¿Cómo fabricar cosas que se sostienen entre sí? Las ciencias sociales, la estadística y el Estado», Archipiélago, 20: 19-32.

28 Tan es así, que el propio término 'root' -el mismo empleado para esa 'square root' con que se construye $\sqrt{-1}$ ' - se usa en slang inglés como sinónimo de nuestras correspondientes versiones soeces de 'pene'. Así lo data el Oxford English Dictionary desde, al menos, un año tan poco posmoderno como el de 1846. $Y$ de ese lenguaje ordinario lo toma, por ejemplo, $K$ Millet, otro autor tan poco posmoderno como para definir la inteligencia como 'masculinidad mental' y animar a los buenos escritores a que den 'ejemplo viril' al escribir, pues 'style is root', es decir, 'el estilo es el pene' (Sexual Politics, III, vii, 329). Si es demasiado pedir a ciertos físicos que hagan excursiones históricas que les lleven al significado de sus conceptos, si también parece demasiado hacerlas a la calle y escuchar a la gente, al menos sí deberían darse una vuelta por la biblioteca general de su universidad antes de seguir añadiendo pedantería e ignorancia a la ignorancia y pedantería que dicen querer combatir. 
Esteva, Gustavo (1995): «El secreto del desarrollo», Coatepec, Revista de la Universidad Autónoma del Estado de México, 1: 50-63.

Fernández, James W. (ed.) (1991): Beyond Metaphor. The Theory of Tropes in Antropology, Stanford University Press, Stanford.

FouCaULT, Michel (1968): Las palabras y las cosas, Siglo XXI, Madrid.

- (1978): «Nietzsche, la genealogía, la historia», en Microfisica del poder, Las Ediciones de La Piqueta, Madrid.

Graclán, Baltasar (1998): Arte de ingenio, Tratado de la Agudeza, Cátedra, Madrid.

Hallyn, Fernand (1987): La structure poétique du monde: Copernic, Kepler, Seuil, Paris.

HAYLER, Katherine (1984): The Cosmic Web: Scientific Field Models and Literary Strategies in the Twentieth Century, Cornell University Press.

- (1993): La evolución del caos, Gedisa, Barcelona.

Hesse, Mary (1966): Models and Analogies in Science, University of Notre Dame Press, Notre Dame.

Hidalgo-SeRna, Emilio (1993): El pensamiento ingenioso en Baltasar Gracián, Anthropos, Barcelona.

Holton, Gerald (1978): The Scientific Imagination: Case Studies, Cambridge University Press, Cambridge.

Johnson, Mark (1991): El cuerpo en la mente, Debate, Madrid.

KoYRÉ, Alexandre (1955): «Attitude esthétique et pensée scientifique», Critique, $\mathrm{n}^{\circ}{ }^{100 \text { - }}$ 101, pp. 835-847.

LAKOFF, George (1998): «Guerra y metáfora: el sistema metafórico utilizado para justificar la Guerra del Golfo», Bitarte, San Sebastián, julio 1998.

LakofF, G. y Johnson, M. (1991): Metáforas de la vida cotidiana, Cátedra, Madrid.

LiZCANO, Emmánuel (1992): «De Foucault a Serres: notas para una arqueología de las matemáticas», Theoria, 2. ${ }^{\text {a }}$ época, VII(1992)16-17-18: 499-507.

- (1993): Imaginario colectivo y creación matemática. La construcción social de número, el espacio y lo imposible en China y en Grecia, Gedisa, Barcelona.

- (1995): «Raíces culturales de los números negativos y el cero», Actas de las Primeras Jornadas para el Aprendizaje y la Enseñanza de las Matemáticas, Ed. Sociedad Emma Castelnuovo, Madrid.

- (1996): «La construcción retórica de la imagen pública de la tecnociencia: impactos, invasiones y otras metáforas", Política y Sociedad, 23:137-146.

LOCKE, D. (1992): La ciencia como escritura, Cátedra, Madrid.

LATOUR, B. (1992): Ciencia en acción, Labor, Barcelona.

MCCLOSKEY, Donald M. (1990): La retórica de la economía, Alianza, Madrid.

NIETZSCHE, Friedrich (1990): Sobre verdad y mentira en sentido extramoral, Tecnos, Madrid.

PanOFSky, Erwin (1954): Galileo as a Critic of the Arts, Martinus Nijhoff, La Haya.

Parkin, D. (1982): Semantic Anthropology, Academic Press, Londres.

PloEg, Jan Douwe van der (1990): «Sistemas de conocimiento, metáfora y campo de interacción: el caso del cultivo de la patata en el altiplano peruano», Agricultura y sociedad, 56: 143-165.

Pörksen, Uwe (1995): «La matematización del lenguaje cotidiano", Archipiélago, 20: 59-68.

PRETA, Lorena (comp.) (1993): Imágenes y metáforas de la ciencia, Alianza, Madrid.

SAPIR, J. David y J. Christopher CROCKER (eds.) (1977): The Social Use of Metaphor. Essays on the Antropology of Rhetoric, University of Pennsylvania Press, Pennsylvania.

SERres, M. (1967): «Les Anamnèses mathématiques», Archives internationales d'histoire des sciences, 78-79: 3-38.

Sokal, A. y BRicmont, J. (1997): Impostures intellectuelles, Odile Jacob, París (Traducción española en Paidós, Barcelona, 1999).

SPERBER, Dan (1978): El simbolismo en general, Promoción Cultural, Barcelona. 
STEngers, Isabelle (1987): D'une science à l'autre. Des concepts nomades, Seuil, Paris.

VATIN, François (1993): Le travail. Economie et physique. 1780-1830, PUF, Paris.

Woolgar, S. (1992): Ciencia: abriendo la caja negra, Anthropos, Barcelona.

\title{
RESUMEN
}

Aquí se propone un método de análisis de textos y discursos basado en una hermenéutica sociológica de las metáforas usadas en los mismos. El analizador central son aquellas metáforas ya cristalizadas como expresiones del lenguaje corriente o como conceptos técnicos o científicos. La eventual potencia del método se basa en la asunción de dos hipótesis básicas: 1) que todo concepto es un concepto metafórico y 2) que toda metáfora $-y$, por tanto, todo concepto- es una institución social.

Sin embargo, la concepción heredada excluye de la actividad metáforica precisamente aquellas determinaciones sociales y culturales que la constituyen, por lo que se impone una radical reelaboración conceptual de la metáfora en el sentido que aquí apuntamos. Las metáforas son instituciones sociales cuya doble actividad -instuyente (metáforas vivas) e instituida (metáforas zombies)- nos permite acceder a los presupuestos, intereses, estrategias, conflictos... sociales y culturales de los grupos que las construyen o las utilizan. Junto a otros ejemplos tomados de diferentes ciencias, ensayamos un análisis socio-metafórico detallado de alguna expresión corriente y de un par de conceptos (el de 'resta' y el de 'raíz cuadrada') tomados de la disciplina que suele tenerse como aquélla de menor contenido metáforico y social: las matemáticas.

Merece especial atención el análisis reflexivo del sustrato metafórico y social de los conceptos habituales en las propias ciencias sociales. Así como los efectos sociales derivados de la reinserción en el lenguaje ordinario de los conceptos que las ciencias han elaborado a partir del mismo.

\begin{abstract}
A sociological hermeneutics of metaphor is proposed as a method for text and discours analysis. The key analyzer are the crystallized metaphors both in ordinary language and in technic or scientific concepts. Power of method rests on two hypotesis: 1) every concept is a metaphorical one, and 2) every metaphor -and then every concept-is a social institution.

But inherited theoretical tradition puts away from metaphorical activity just his social and cultural constituents. A radical conceptual reprocessing is required: metaphors are social institutions whose two-sided activity -instituent (living metaphors) and institued (zombies metaphors)- allows to know social and cultural prejudices, interests, strategies and conflicts peculiars to groups that build up or use such methapors. Besides other examples taken on diferent sciences, we carry out a sistematic analyisis of some ordinary utterances and two mathematical terms ('to substract' and 'square root') supossed not to be metaphorical nor social terms at all.

Special interest deserves a reflexive analyisis of social and metaphorical grounds of usual concepts in social sciences. Social effects of ordinary language reinscription of scientific concepts are also considered.
\end{abstract}

